\title{
Reaction morphologies developed by nickel aluminides in type II hot corrosion conditions: the effect of chromium
}

Thomas Gheno ${ }^{a^{*}}$, Maryam Zahiri Azarb, Arthur H. Heuerb, Brian Gleeson ${ }^{\mathrm{a}}$

aDepartment of Mechanical Engineering and Materials Science, University of Pittsburgh, Pittsburgh PA 15261

bDepartment of Materials Science and Engineering, Case Western Reserve University, Cleveland OH 44106

*Corresponding author. Tel: +1-412-624-9720; Fax: +1-412-624-4846

Email address: thg14@pitt.edu (T. Gheno)

\begin{abstract}
The short-term reaction of $\mathrm{Ni}-36 \mathrm{Al}$ (at. \%) and Ni-36Al-5Cr alloys with $\mathrm{Na}_{2} \mathrm{SO}_{4}$ in $\mathrm{O}_{2}-0.1 \%$ $\mathrm{SO}_{2}$ at $700{ }^{\circ} \mathrm{C}$ was studied by SEM and TEM. Local failure of the protective scale on NiAl led to nodule development via internal oxidation. Conversely, NiAlCr underwent a uniform attack involving internal sulfidation, porous scale growth, and $\mathrm{NiO}$ and $\mathrm{Al}_{2} \mathrm{O}_{3}$ dissolution into the sulfate. The roles of gas and sulfate compositions were studied by comparing exposures to $\mathrm{Na}_{2} \mathrm{SO}_{4}, \mathrm{Na}_{2} \mathrm{SO}_{4}-\mathrm{MgSO}_{4}$ and $\mathrm{Na}_{2} \mathrm{SO}_{4}-\mathrm{Cr}_{2} \mathrm{O}_{3}$ deposits in air and $\mathrm{O}_{2}-0.1 \% \mathrm{SO}_{2}$. The effect of $\mathrm{Cr}$ in preventing passivation during early-stage exposure was associated with a coupled dissolution of $\mathrm{NiO}$ and $\mathrm{Cr}_{2} \mathrm{O}_{3}$.
\end{abstract}

Keywords: A. molten salts; A. nickel; C. hot corrosion; C. selective oxidation; C. sulphidation

\section{Introduction}

Accelerated attack of high temperature alloys by molten sulfate deposits, generally referred to as hot corrosion, has long been recognized as an important concern in the operation of gas turbines for aircraft and marine propulsion systems [1,2]. Mechanistic aspects of the hot corrosion process, as well as alloy and coating compositional factors and mitigation strategies, have been reviewed multiple times, e.g. in Refs. [3-7], so that the subject is only briefly discussed here. Two temperature regimes are distinguished based on the melting point $\left(\mathrm{T}_{\mathrm{m}}\right)$ of the deposited sulfate, typically $\mathrm{Na}_{2} \mathrm{SO}_{4}\left(\mathrm{~T}_{\mathrm{m}}=884^{\circ} \mathrm{C}\right)$ : type I at temperatures above $\mathrm{T}_{\mathrm{m}}$, and type II below $\mathrm{T}_{\mathrm{m}}$. In type II conditions, a minimum amount of $\mathrm{SO}_{3}$ is required in the gas to stabilize a liquid sulfate [8]. No hot corrosion is expected below the eutectic temperature (e.g., $\left.\mathrm{T}_{\mathrm{e}}\left(\mathrm{Na}_{2} \mathrm{SO}_{4}-\mathrm{NiSO}_{4}\right)=671^{\circ} \mathrm{C}, \mathrm{T}_{\mathrm{e}}\left(\mathrm{Na}_{2} \mathrm{SO}_{4}-\mathrm{CoSO}_{4}\right)=565^{\circ} \mathrm{C}\right)$. Conversely, sulfates evaporate rapidly at elevated temperatures, such that dry corrosion (e.g. oxidation) prevails above about $1050^{\circ} \mathrm{C}$.

Hot corrosion essentially occurs as oxides, which would otherwise form a compact scale on an alloy surface, dissolve into the molten salt. In this regard, diagrams indicating which metal species will be most stable in given conditions of sulfate composition and temperature have proved useful in discussing reaction mechanisms. Following Goebel and Pettit [9], $p_{\mathrm{SO}_{3}}$ and $p_{\mathrm{O}_{2}}$ were used as coordinates to plot two-dimensional Na-M-O-S ( $\mathrm{M}=\mathrm{Al}$, $\mathrm{Ni}$ and $\mathrm{Cr}$ ) stability diagrams at $700{ }^{\circ} \mathrm{C}$ in Figure 1 . The construction of such diagrams has 
been discussed in detail by $\mathrm{Li}$ et al. [14]. Taking the example of $\mathrm{Al}$, the basic and acidic reactions of $\mathrm{Al}_{2} \mathrm{O}_{3}$ with $\mathrm{Na}_{2} \mathrm{SO}_{4}$ are written

and

$$
\mathrm{Al}_{2} \mathrm{O}_{3}+\mathrm{Na}_{2} \mathrm{SO}_{4}=2 \mathrm{NaAlO}_{2}+\mathrm{SO}_{3}
$$

$$
\mathrm{Al}_{2} \mathrm{O}_{3}+3 \mathrm{SO}_{3}=\mathrm{Al}_{2}\left(\mathrm{SO}_{4}\right)_{3}
$$

respectively, and represented by vertical lines $\left(\mathrm{PSO}_{3}=\right.$ constant $)$ in Figure $1 \mathrm{a}$, where the activity of all compounds is taken as unity. These $p_{\mathrm{SO}_{3}}$ values define whether a sulfate is considered acidic or basic, relative to a given metal oxide. The activities of $\mathrm{SO}_{3}$ and $\mathrm{Na}_{2} \mathrm{O}$ are related through the sulfate dissociation equilibrium

$$
\mathrm{Na}_{2} \mathrm{SO}_{4}=\mathrm{Na}_{2} \mathrm{O}+\mathrm{SO}_{3}
$$

Metal cations and oxyanions have some solubility in solid and liquid $\mathrm{Na}_{2} \mathrm{SO}_{4}$, and in the case of Al the basic and acidic dissolution reactions may be written

$$
\mathrm{Al}_{2} \mathrm{O}_{3}+\underline{\mathrm{O}^{2-}}=\underline{2 \mathrm{AlO}_{2}^{-}}
$$

and

$$
\mathrm{Al}_{2} \mathrm{O}_{3}=2 \underline{\mathrm{Al}^{3+}}+3 \underline{\mathrm{O}^{2-}}
$$

respectively (solutes are underlined). A relation between the activity of oxide ions and $p_{\mathrm{SO}_{3}}$ is obtained by considering the equilibrium

which is equivalent to Eq. (3).

$$
\mathrm{SO}_{4}^{2-}=\mathrm{O}^{2-}+\mathrm{SO}_{3}
$$

The Ni and Co systems were studied in detail by Luthra and Shores [8] and Misra et al. [15]. As the concentration of metal sulfate in solid $\mathrm{Na}_{2} \mathrm{SO}_{4}$ reaches the solidus composition, and inasmuch as its activity is less than unity, a liquid is formed at a lower $p_{\mathrm{SO}_{3}}$ than that required to stabilize the pure metal sulfate. This behavior is particularly important in type II conditions and is illustrated for $\mathrm{Ni}$ in Figure 1b. In this figure, the dotted vertical line represents the $p_{\mathrm{SO}_{3}}$ at equilibrium between $\mathrm{NiO}(\mathrm{s}), \mathrm{Na}_{2} \mathrm{SO}_{4}-\mathrm{NiSO}_{4}(\mathrm{~s})$ and $\mathrm{Na}_{2} \mathrm{SO}_{4}-\mathrm{NiSO}_{4}$ (l) estimated by Misra et al. [15] using a regular solution model for the liquid. The equilibrium $p_{\mathrm{SO}_{3}}$ in a $\mathrm{O}_{2}-0.1 \% \mathrm{SO}_{2}$ gas mixture at $700{ }^{\circ} \mathrm{C}$ is not high enough to stabilize pure $\mathrm{NiSO}_{4}(\mathrm{~s})$, but will allow a liquid $\mathrm{Na}_{2} \mathrm{SO}_{4}-\mathrm{NiSO}_{4}$ solution to form when $\mathrm{NiO}$ is contacted with $\mathrm{Na}_{2} \mathrm{SO}_{4}$.

Another essential aspect is that dissolution or fluxing of an oxide, whether predominantly acidic or basic, will occur to some extent at any $\mathrm{SO}_{3}$ level, with the solute activities being determined by the ambient $p_{\mathrm{SO}_{3}}$. Solubility plots for various metal cations and oxyanions in molten $\mathrm{Na}_{2} \mathrm{SO}_{4}$ as a function of $p_{\mathrm{SO}_{3}}$ at $927^{\circ} \mathrm{C}$ were published by Rapp and coworkers [4]. Since the kinetics of dissolution processes are limited by ionic transport in the melt [16], activity gradients develop in the melt during hot corrosion of an alloy. In conditions where a negative solubility gradient [17] is established, the scale formed by oxidation of an alloy will dissolve at the oxide/melt interface and re-precipitate as a nonprotective oxide within the melt.

Type I hot corrosion of Ni-base alloys proceeds according to two main modes of attack, as documented by Goebel et al. [2]. Adopting the terminology of Birks et al. [6], these are (i) basic fluxing, where the consumption of $O$ and $S$ at the oxide/melt interface due to oxidation and sulfidation leads to a local increase in the melt basicity, to a level where basic dissolution is significant; and (ii) alloy-induced acidic fluxing, where the dissolution of refractory metal oxides such as $\mathrm{MoO}_{3}$ or $\mathrm{WO}_{3}$ gives rise to locally acidic conditions, which destabilizes protective oxides such as $\mathrm{NiO}$ or $\mathrm{Al}_{2} \mathrm{O}_{3}$. 
More recently, the continuous increase of turbine service temperatures has led to type II hot corrosion of previously immune parts such as disks. The associated reaction mechanism, gas-phase induced acidic fluxing, is much less understood than type I mechanisms. Luthra [18,19] proposed a model for Co and Co-base alloys, but it is not directly applicable to Ni-base alloys. The work on $\mathrm{Ni}$ has mostly concerned gas atmospheres with $\mathrm{SO}_{2}-\mathrm{SO}_{3}$ contents much higher than would be found in a gas turbine. Lillerud and Kofstad [20] used an $\mathrm{O}_{2}-4 \% \mathrm{SO}_{2}$ composition at different pressures at $700{ }^{\circ} \mathrm{C}$, where $\mathrm{Ni}_{3} \mathrm{~S}_{2}$ formed within the $\mathrm{NiO}$ scale, and rapid $\mathrm{Ni}$ diffusion in the sulfide caused high reaction rates, much like in gaseous oxidation-sulfidation processes [21]. A recent study [22] dealt with the reaction of $\mathrm{Ni}$ with and without $\mathrm{Na}_{2} \mathrm{SO}_{4}$ in $\mathrm{O}_{2}-0.1 \% \mathrm{SO}_{2}$ at $700{ }^{\circ} \mathrm{C}$, where $\mathrm{NiSO}_{4}$ (s) is not stable but a liquid $\mathrm{Na}_{2} \mathrm{SO}_{4}-\mathrm{NiSO}_{4}$ solution is formed. Little is known about the effect of alloying elements in these conditions. Recent work on Ni-base alloys at $700{ }^{\circ} \mathrm{C}$ concerned commercial materials, and focused on scale growth mechanisms [23], or on statistical lifetime models [24,25]; yet current mechanistic understanding remains limited.

Universally present in heat-resisting Ni-base materials, $\mathrm{Cr}$ has long been acknowledged as very beneficial to type I hot corrosion resistance, particularly when a high content is present in MCrAlY alloys [5]. A recent study [26] suggested that $\mathrm{Cr}$ may also be effective when added to $\beta$-NiAl in type II conditions. The present paper is aimed at further elucidating the role of $\mathrm{Cr}$ in the reaction mechanism of nickel aluminides in an oxygen-rich, $\mathrm{O}_{2}-0.1 \% \mathrm{SO}_{2}$ gas mixture at $700{ }^{\circ} \mathrm{C}$, with a focus on the early-stage reaction morphologies. We will demonstrate that:

1. Cr-free NiAl is not prone to hot corrosion at least initially, but is instead subject to localized internal oxidation aside protective $\mathrm{Al}_{2} \mathrm{O}_{3}$ scaling;

2. Cr-containing NiAl, by contrast, is unable to passivate and immediately undergoes uniform hot corrosion;

3. the effect of $\mathrm{Cr}$ in facilitating oxide dissolution in $\mathrm{Na}_{2} \mathrm{SO}_{4}$ prevails over its ability to promote $\mathrm{Al}_{2} \mathrm{O}_{3}$ scale establishment, as is observed in the absence of $\mathrm{Na}_{2} \mathrm{SO}_{4}$;

4. the gas $p_{\mathrm{SO}_{3}}$ is critical to the mode of attack, regardless of whether the applied deposit is initially solid or liquid; in basic conditions, applying a liquid deposit is necessary for the attack to occur, whereas in acidic conditions, where low-melting solutions can eventually form, applying a liquid deposit simply accelerates the attack without changing the mechanism.

\section{Materials and experimental procedures}

Model alloys of nominal compositions $\mathrm{Ni}-36 \mathrm{Al}$ and $\mathrm{Ni}-36 \mathrm{Al}-5 \mathrm{Cr}$ (at. \%), referred to hereafter as NiAl and NiAlCr, were prepared at the Materials Preparation Center of Ames Laboratory [27] by Ar arc melting, followed by drop casting into $10 \mathrm{~mm}$ diameter rods, and then homogenizing for $6 \mathrm{~h}$ at $1200{ }^{\circ} \mathrm{C}$ and $48 \mathrm{~h}$ at $1150{ }^{\circ} \mathrm{C}$ in vacuum. Specimens approximately $1 \mathrm{~mm}$ thick were cut and ground to a P1200-grit finish using SiC paper, then degreased with detergent and ultrasonically cleaned in ethanol before exposure.

Isothermal corrosion experiments were conducted at $700{ }^{\circ} \mathrm{C}$ in a horizontal tube furnace, in flowing dry air and $\mathrm{O}_{2}-0.1 \% \mathrm{SO}_{2}$ (referred to hereafter as $\mathrm{O}_{2}-0.1 \mathrm{SO}_{2}$ ), with and without deposits. Gas flow rates were $30 \mathrm{ml} \mathrm{min}^{-1}$, with a total pressure slightly over $1 \mathrm{~atm}$. 
The $\mathrm{O}_{2}-\mathrm{SO}_{2}$ mixture was passed through a platinized honeycomb catalyst located directly upstream of the specimens in the hot zone, allowing the otherwise sluggish reaction

$$
\mathrm{SO}_{2}+\frac{1}{2} \mathrm{O}_{2}=\mathrm{SO}_{3}
$$

to proceed, with an equilibrium $p_{\mathrm{SO}_{3}}$ calculated to be $7.1 \times 10^{-4} \mathrm{~atm}$ at $700{ }^{\circ} \mathrm{C}$ from data in Ref. [10]. Deposits were prepared by mixing laboratory grade reagents in deionized water, and then applying the solution on the specimens using a dropper. Evaporation by heating the specimens on a hot plate produced approximately uniform $2.8 \pm 0.5 \mathrm{mg} \mathrm{cm}^{-2}$ deposits. In some instances deposits were applied by spraying the aqueous solution on preheated specimens. The deposition method was verified to have no significant effect on the corrosion behavior. The alloys were exposed to pure $\mathrm{Na}_{2} \mathrm{SO}_{4}$ and a $\mathrm{Na}_{2} \mathrm{SO}_{4}-48 \mathrm{~mol} \% \mathrm{MgSO}_{4}$ mixture, the latter of which is fully liquid at $700{ }^{\circ} \mathrm{C}$ [28].

Since hot corrosion processes are particularly prone to variability, experiments were run in duplicates or triplicates to ensure reproducibility of the results. After exposure, deposits were washed off from some specimens for surface SEM observations, FIB milling and TEM work. On other specimens, polished sections were prepared using water-free cutting fluid and polishing suspensions to retain any water-soluble products. In some cases, thin foils containing the metal, oxide and retained salt were prepared by FIB milling and observed by TEM.

Alloy phase constitutions before and after reaction were studied by XRD using a Panalytical Empyrean instrument, with Co radiation $\left(K_{\alpha 1}=1.789 \AA\right.$ Å). Oxidized surfaces were examined by photo-stimulated luminescence spectroscopy (PSLS), which allows $\gamma, \theta$ and $\alpha$ polymorphs of $\mathrm{Al}_{2} \mathrm{O}_{3}$ to be distinguished [29], using a $633 \mathrm{~nm}$ HeNe laser in a Renishaw inVia Raman microscope. Reaction products were studied by SEM with a JEOL JSM 6510 instrument, equipped with an Oxford X-Max SDD EDS detector and INCA analysis software. Thin foils were prepared by FIB milling with a FEI Nova NanoLab 200 instrument, and TEM work was conducted on a Zeiss Libra 200FE instrument operated at $200 \mathrm{kV}$, equipped with HAADF and Si-Li EDS detectors.

\section{Results}

\subsection{Phase constitution of the alloys and their oxidation products}

Phase constitutions determined by XRD (Figure 2) and SEM before and after $20 \mathrm{~h}$ oxidation in dry air at $700{ }^{\circ} \mathrm{C}$ are given in Table 1 , together with literature data. Slow cooling from the high annealing temperature $\left(1150^{\circ} \mathrm{C}\right)$, where the alloys fall within the single-phase $\beta$-NiAl region, produced $\mathrm{L} 10$ martensite and intergranular $\gamma^{\prime}-\mathrm{Ni}_{3} \mathrm{Al}$ in the $\mathrm{NiAl}$ alloy in the asreceived condition. Oxidation to form $\mathrm{Al}_{2} \mathrm{O}_{3}$ scales caused $\mathrm{Al}$ depletion and $\gamma^{\prime}$ formation in the alloy subsurface for both compositions. During the $700{ }^{\circ} \mathrm{C}$ heat treatment, intergranular $\gamma^{\prime}$ precipitated in NiAlCr, but the grains retained their $\beta$ structure. In contrast, the martensite present in NiAl decomposed into a very fine microstructure of $\mathrm{Ni}_{5} \mathrm{Al}_{3}$ and $\gamma^{\prime}$ precipitates in a $\beta$ matrix, shown in Figure 3.

Due to the low oxide growth rate at the reaction temperature of $700{ }^{\circ} \mathrm{C}$, the structure of the $\mathrm{Al}_{2} \mathrm{O}_{3}$ scales could not be determined with satisfactory reliability on the basis of the 
XRD patterns recorded using grazing incidence: no $\alpha-\mathrm{Al}_{2} \mathrm{O}_{3}$ reflections were clearly detected, while some small peaks compatible with $\theta-\mathrm{Al}_{2} \mathrm{O}_{3}$ or $\gamma-\mathrm{Al}_{2} \mathrm{O}_{3}$ were found. Similarly, analysis of the oxidized sample surfaces by PSLS yielded no $\alpha-\mathrm{Al}_{2} \mathrm{O}_{3}$ peaks, only faint $\theta$ $\mathrm{Al}_{2} \mathrm{O}_{3}$ peaks and a broad low-intensity peak compatible with $\gamma-\mathrm{Al}_{2} \mathrm{O}_{3}$. Given that $\alpha$ luminescence is intrinsically 10-12 times more intense than that of $\theta$ [29], and on the basis of both the PSLS and XRD results, it is concluded that the oxide scales grown on both alloys in air at $700{ }^{\circ} \mathrm{C}$ were mostly transition aluminas, $\gamma$ or $\theta$. This is consistent with earlier reports of $\gamma-\mathrm{Al}_{2} \mathrm{O}_{3}$ formation on equiatomic NiAl at this temperature [31].

\subsection{Exposure to $\mathrm{Na}_{2} \mathrm{SO}_{4}$ in $\mathrm{O}_{2}-\mathrm{O} .1 \mathrm{SO}_{2}$}

After $2 \mathrm{~h}$ exposure to $\mathrm{Na}_{2} \mathrm{SO}_{4}$ in $\mathrm{O}_{2}-0.1 \mathrm{SO}_{2}$, NiAl formed a thin external scale and small intrusions ( $1 \mu \mathrm{m}$ deep or less). As shown in Figure 4, the intrusions consisted of $\gamma-\mathrm{Al}_{2} \mathrm{O}_{3}$ and were enriched in $\mathrm{S}$ at the interface with the metal. The sulfate deposit was generally not adherent to the specimen after reaction, except where intrusions had formed, where it contained some $\mathrm{Ni}$ and $\mathrm{Al}$ (1-5 at. \%). After $20 \mathrm{~h}$, scattered nodules of varying size but equivalent morphology were observed (Figure 5). The bicone-shaped nodules consisted of internal $\gamma-\mathrm{Al}_{2} \mathrm{O}_{3}$ in an $\mathrm{Al}$-depleted metal matrix near the reaction front, and a $\mathrm{NiO}-\mathrm{NiAl}_{2} \mathrm{O}_{4}$ mixture toward the surface. The oxides were identified by TEM-SAD (not shown here). A thin region of porous $\mathrm{NiO}$ was sometimes found at the surface of the largest nodules. The inter-particle region consisted of both $\gamma$ and $\gamma^{\prime}$, with compositions (12 and 26 at. \% Al) consistent with $\gamma-\gamma$ ' equilibrium at $700{ }^{\circ} \mathrm{C}$ [30]. Traces of S (1 at. \% or less) were sometimes detected in the oxide by SEM-EDS. No sign of repassivation was found at the reaction front of the smaller nodules; rather, local disruption of the protective scale and nodule development must have occurred continuously during the exposure. Regions were visible on the same sample where the internal attack was in a very early stage, as exemplified in the insert of Figure 5. Most of the surface was still covered by an external $\mathrm{Al}_{2} \mathrm{O}_{3}$ scale after $20 \mathrm{~h}$.

In contrast, after $2 \mathrm{~h}$ reaction, the NiAlCr alloy was covered by a continuous, $2-5 \mu \mathrm{m}$ mixed oxide scale (Figure 6a). The reaction product was Al-rich but also contained small amounts (2-5 at. \%) of $\mathrm{Cr}, \mathrm{Ni}, \mathrm{Na}$ and $\mathrm{S}$. Some regions were enriched in $\mathrm{Ni}$ and $\mathrm{S}$. Chemical imaging (Figure $6 \mathrm{~b}$ ) revealed a considerable $S$ enrichment in the oxide around the metal/oxide interface. This was much greater than in the $\mathrm{Cr}$-free NiAl, as TEM-EDS analysis of the interfacial region after the same exposures yielded 24 at. $\% \mathrm{~S}$ for NiAlCr, compared to 3 at. $\% \mathrm{~S}$ for NiAl. In addition, NiAlCr developed internal Cr-rich sulfides. Variable amounts of $\mathrm{Al}$ and $\mathrm{Ni} \mathrm{(2-5} \mathrm{at.} \mathrm{\% )} \mathrm{were} \mathrm{found} \mathrm{in} \mathrm{the} \mathrm{sulfate} \mathrm{located} \mathrm{directly} \mathrm{above} \mathrm{the} \mathrm{scale.} \mathrm{The}$ corrosion products developed after $6.5 \mathrm{~h}$ and $20 \mathrm{~h}$ reaction (Figure 7) were similar to that observed after $2 \mathrm{~h}$. Sodium and S were found throughout the Al-rich oxide scale, which also included Ni-rich sulfide regions. Ahead of the reaction front, sulfides identified as $(\mathrm{Al}, \mathrm{Cr})_{3} \mathrm{~S}_{4}$ thiospinel by TEM precipitated in an Al-depleted $\gamma^{\prime}$ matrix. After $6.5 \mathrm{~h}$, the sulfate deposit was separated in two distinct zones: near the scale surface, it contained relatively high amounts of $\mathrm{Al}$ and $\mathrm{Ni} \mathrm{(3-8} \mathrm{at.} \mathrm{\% ),} \mathrm{while} \mathrm{outside} \mathrm{and} \mathrm{away} \mathrm{from} \mathrm{the} \mathrm{scale} \mathrm{surface,} \mathrm{no}$ significant Al was detected, and the $\mathrm{Ni}$ content was around 1 at. \%. These Ni levels correspond to liquid and solid sulfate solutions, respectively (see $\mathrm{Na}_{2} \mathrm{SO}_{4}-\mathrm{NiSO}_{4}$ phase diagram in Ref. [32]). Porous NiO was embedded in the sulfate near the scale surface. After 
$20 \mathrm{~h}$, the sulfate deposit contained variable amounts of $\mathrm{Ni} \mathrm{(1-5} \mathrm{at.} \mathrm{\% ),} \mathrm{Al}$ (1-15 at. \%) and $\mathrm{Cr}$ (1-3 at. \%). A porous oxide developed within the deposit both at the scale surface and at the interface with the gas. These oxide regions were rich in $\mathrm{Ni}$ and also contained some Al. The reaction morphologies observed after $20 \mathrm{~h}$ reaction of the NiAlCr specimens presented some local variations. The outermost oxide layer had thicknesses ranging from submicron (Figure $7 \mathrm{~b}$ ) to over $10 \mu \mathrm{m}$. In the latter case, little or no deposit was left, and both the inner oxide thickness and the internal sulfidation depth were greater (Figure 7c).

\subsection{Exposure to $\mathrm{Na}_{2} \mathrm{SO}_{4}-\mathrm{MgSO}_{4}$}

Additional experiments were carried out to investigate the role played by the physical state (solid vs liquid) and chemistry (acid vs basic) of the deposit. Specifically, specimens of NiAl and $\mathrm{NiAlCr}$ were reacted with $\mathrm{Na}_{2} \mathrm{SO}_{4}$ in dry air, and with $\mathrm{Na}_{2} \mathrm{SO}_{4}-\mathrm{MgSO}_{4}$ in dry air and $\mathrm{O}_{2}$ $0.1 \mathrm{SO}_{2}$, all for $20 \mathrm{~h}$. A eutectic $\mathrm{Na}_{2} \mathrm{SO}_{4}-\mathrm{MgSO}_{4}$ mixture $\left(\mathrm{T}_{\mathrm{e}}=670^{\circ} \mathrm{C}\right)$ was used to ensure that the deposit was liquid at the reaction temperature of $700{ }^{\circ} \mathrm{C}$.

Exposure of both $\mathrm{NiAl}$ and $\mathrm{NiAlCr}$ to $\mathrm{Na}_{2} \mathrm{SO}_{4}$ in dry air produced external $\mathrm{Al}_{2} \mathrm{O}_{3}$ scales, with scattered intrusions 1-2 $\mu \mathrm{m}$ deep ( $\mathrm{NiAl}$ shown in Figure 8a). The sulfate deposit directly above the intrusions contained some $\mathrm{Ni}$ and $\mathrm{Al}$ (1-5 at. \%). Under the $\mathrm{Na}_{2} \mathrm{SO}_{4}$ $\mathrm{MgSO}_{4}$ deposit, NiAl formed an external $\mathrm{Al}_{2} \mathrm{O}_{3}$ scale with small intrusions and isolated nodules 20-30 $\mu \mathrm{m}$ deep in air (Figure 8b), but sustained massive degradation in $\mathrm{O}_{2}-0.1 \mathrm{SO}_{2}$ (Figure 9a). The nodules formed in air comprised sulfides at the reaction front, Mg-rich aluminates toward the surface and an outermost $\mathrm{MgO}$ layer. In $\mathrm{O}_{2}-0.1 \mathrm{SO}_{2}$, the corrosion product consisted of internal Al-rich oxide at the reaction front, and mixed Al-Ni oxides with $\mathrm{S}$ toward the surface (Figure $9 \mathrm{a}$ ). The penetration depth was approximately uniform, but regions of non-oxidized alloy were also found within the internally oxidized zone. This corrosion product extended deeper but was of a similar constitution as the nodules formed under $\mathrm{Na}_{2} \mathrm{SO}_{4}$ in $\mathrm{O}_{2}-0.1 \mathrm{SO}_{2}$.

Exposure of NiAlCr to $\mathrm{Na}_{2} \mathrm{SO}_{4}-\mathrm{MgSO}_{4}$ resulted in external $\mathrm{Al}_{2} \mathrm{O}_{3}$ growth in air, while significant corrosion was observed in $\mathrm{O}_{2}-\mathrm{O}_{1} \mathrm{SO}_{2}$ (Figure $9 \mathrm{~b}$ ). The reaction product was structurally similar to that formed with $\mathrm{Na}_{2} \mathrm{SO}_{4}$ in $\mathrm{O}_{2}-\mathrm{O}_{2} \mathrm{SO}_{2}$ (compare with Figure 7), as it featured an outermost, porous Ni-rich oxide layer, an inner mixed oxide layer, and internal sulfides in an Al-depleted $\gamma^{\prime}$ matrix.

\section{Discussion}

The results obtained after relatively short-term exposure to $\mathrm{Na}_{2} \mathrm{SO}_{4}$ in $\mathrm{O}_{2}-0.1 \mathrm{SO}_{2}$ indicated that alloying with $\mathrm{Cr}$ caused a substantial change in the reaction mechanism, from a localized internal oxidation type of attack ( $\mathrm{NiAl}$ ) to a relatively uniform hot corrosion process ( $\mathrm{NiAlCr}$ ). A remarkable manifestation of this change is the formation of a porous, mixed oxide layer within $2 \mathrm{~h}$ exposure on NiAlCr (Figure 6); while on NiAl, external $\mathrm{Al}_{2} \mathrm{O}_{3}$ formation persisted up to at least $100 \mathrm{~h}$ alongside the fast growing nodules. The simultaneous presence of both an external $\mathrm{Al}_{2} \mathrm{O}_{3}$ scale and nodules of various sizes on the binary alloy (Figure 5) indicates that new nodules nucleated continuously throughout the exposure, and that their growth remained rapid. In contrast, in the case of $\mathrm{NiAlCr}$, external $\mathrm{Al}_{2} \mathrm{O}_{3}$ either did not form or failed within $2 \mathrm{~h}$, but the extent of corrosion is relatively low in 
the longer term. Indeed, in a recent study in which experiments were conducted in the same conditions [26], weight gains were found to be lower for NiAlCr than for NiAl after $100 \mathrm{~h}$ reaction. The present discussion is concerned with reaction morphologies and associated mechanistic aspects in the early stages, and less so with reaction kinetics or longer term performance.

In Ref. [26], the better resistance of NiAlCr over NiAl was tentatively attributed to the ability of $\mathrm{Cr}$ to exclude transient oxidation of $\mathrm{Ni}$ and favor the rapid establishment of $\mathrm{Al}_{2} \mathrm{O}_{3}$ during the early stage of the exposure. Although this may be the case in the absence of a deposit, it does not in fact apply to type II hot corrosion conditions, as shown by the present results. Instead of oxidation-related arguments, the present discussion considers the acidbase chemistry of the sulfate deposit - a standpoint which has so far mostly been limited to type I conditions [4], but will be shown here to be also useful in describing type II processes.

\subsection{Reactivity of NiAl}

The reaction of $\mathrm{NiAl}$ with $\mathrm{Na}_{2} \mathrm{SO}_{4}$ in $\mathrm{O}_{2}-0.1 \mathrm{SO}_{2}$ resulted in the local development of biconeshaped nodules of internal $\mathrm{Al}_{2} \mathrm{O}_{3}$ (Figure 5). Such nodules were reported by previous investigators after oxidation of $\beta$-NiAl alloys in quartz ampoules in the presence of buffer metal-oxide mixtures $\left(\mathrm{Cu}-\mathrm{CuO}_{2}, \mathrm{Ni}-\mathrm{NiO}, \ldots\right)$ in the temperature range $500-1000{ }^{\circ} \mathrm{C}[33]$, or in $\mathrm{H}_{2}-\mathrm{H}_{2} \mathrm{~S}-\mathrm{H}_{2} \mathrm{O}$ gas mixtures at $900{ }^{\circ} \mathrm{C}$ [34]. In both cases the inability of the alloy to maintain a protective $\mathrm{Al}_{2} \mathrm{O}_{3}$ scale was attributed to the reaction of $\mathrm{Al}$ with $\mathrm{S}$ [35], although the underlying mechanism was not discussed in detail. Similar nodules were also observed after oxidation in $\mathrm{O}_{2}$ at $1000{ }^{\circ} \mathrm{C}$ of presulfidized $\beta$-NiAl [36]. The formation of porous, internal $\mathrm{Al}_{2} \mathrm{O}_{3}$ was attributed by the latter authors to the oxidation of internal $\mathrm{Al}_{2} \mathrm{~S}_{3}$ that had formed during the presulfidation treatment. According to the interpretation presented, the reaction would generate $\mathrm{SO}_{2}$ and disrupt the $\mathrm{Al}_{2} \mathrm{O}_{3}$, preventing its growth as a compact layer. However, no $\mathrm{Al}_{2} \mathrm{~S}_{3}$ was found in the present study despite careful TEM examination of the nodules. Smialek [37] reported the rapid growth of porous $\mathrm{Al}_{2} \mathrm{O}_{3}$ on highly $\mathrm{S}$ - and $\mathrm{Zr}$ doped $\mathrm{NiAl}$ in air at $1200^{\circ} \mathrm{C}$. An open network of submicron microchannels was argued to allow rapid gas transport. This is a different mode of propagation, but Smialek also concluded that the widespread porosity was due to $\mathrm{SO}_{2}$ evolution. This conclusion could be neither confirmed nor disproved here, but the $\mathrm{S}$ enrichment at the bottom of the Al-rich oxide intrusions formed in the presence of $\mathrm{Na}_{2} \mathrm{SO}_{4}$ (Figure 4) did seem essential to the internal oxidation process.

The importance of $\mathrm{S}$ was confirmed by reacting a $\mathrm{NiAl}$ specimen with $\mathrm{Na}_{2} \mathrm{SO}_{4}$ in $\mathrm{O}_{2}$ $0.1 \mathrm{SO}_{2}$ for $20 \mathrm{~h}$, then washing off the deposit, and heat-treating the specimen again in air with no deposit, all at $700^{\circ} \mathrm{C}$. Successive surface micrographs of the same region are shown in Figure 10: the nodules formed during the sulfate exposure are seen to grow only slightly during the first $20 \mathrm{~h}$ heat-treatment in air, and to not grow significantly thereafter. It is therefore concluded that the process leading to internal, porous $\gamma-\mathrm{Al}_{2} \mathrm{O}_{3}$ formation is not self-sustaining, and that a continuous supply of $S$ is required. The exact nature of the interaction between $\mathrm{S}$ and $\mathrm{Al}$ is not fully understood at present, and deserves further investigation. 
The absence of a significant fluxing process is in itself informative. After $2 \mathrm{~h}$ reaction with $\mathrm{Na}_{2} \mathrm{SO}_{4}$ in $\mathrm{O}_{2}-0.1 \mathrm{SO}_{2}$, small but significant amounts (1-5 at. \%) of $\mathrm{Al}$ and $\mathrm{Ni}$ were measured in the sulfate in contact with the oxide intrusions, and less than 1 at. \% were present in the rest of the deposit. Solubility curves such as those established by Rapp and co-workers [4] at $927{ }^{\circ} \mathrm{C}$ are not available at $700{ }^{\circ} \mathrm{C}$, and it is not known whether the predominant aluminum solute in $\mathrm{Na}_{2} \mathrm{SO}_{4}$ equilibrated with $\mathrm{O}_{2}-0.1 \mathrm{SO}_{2}$ at this temperature $\left(p_{\mathrm{SO}_{3}}=7.1 \times 10^{-4} \mathrm{~atm}\right)$ is $\mathrm{Al}^{3+}$ or $\mathrm{AlO}_{2}^{-}$. Lawson et al. [38] reported a slow acidic dissolution of bulk $\mathrm{Al}_{2} \mathrm{O}_{3}$ with an $\mathrm{O}_{2}-1 \mathrm{SO}_{2}$ mixture at $700{ }^{\circ} \mathrm{C}\left(p_{\mathrm{SO}_{3}}=7.1 \times 10^{-3} \mathrm{~atm}\right)$, whereas there was less reaction under basic conditions. The solubility minimum is at $p_{\mathrm{SO}_{3}}=5 \times 10^{-2} \mathrm{~atm}$ at $927{ }^{\circ} \mathrm{C}$ [39]. With a decrease in temperature, $p_{\mathrm{SO}_{3}}$ for the $\mathrm{NaAlO}_{2} / \mathrm{Al}_{2} \mathrm{O}_{3}$ and $\mathrm{Al}_{2} \mathrm{O}_{3} / \mathrm{Al}_{2}\left(\mathrm{SO}_{4}\right)_{3}$ equilibria decreases, and the minimum solubility shifts towards lower $p_{\mathrm{SO}_{3}}$ values. Based on the Gibbs free energy of reactions (1) and (2), it is expected that a $p_{\mathrm{SO}_{3}}$ of $7.1 \times 10^{-4} \mathrm{~atm}$ will be near the solubility minimum at $700{ }^{\circ} \mathrm{C}$. Thus, the dissolution of $\mathrm{Al}_{2} \mathrm{O}_{3}$ could be either acidic or basic, depending on the local sulfate chemistry; the discussion will return to this point when addressing the NiAlCr alloy. If one only considers the $\mathrm{Na}_{2} \mathrm{SO}_{4}-\mathrm{NiSO}_{4}$ solution, the solidus composition contains 3 at. $\% \mathrm{Ni}$ at $700{ }^{\circ} \mathrm{C}$ [32]. It is therefore concluded that some liquid sulfate was locally present in contact with the oxide intrusions. Even so, the long-term persistence of an $\mathrm{Al}_{2} \mathrm{O}_{3}$ scale alongside the nodules indicates that $\mathrm{Al}_{2} \mathrm{O}_{3}$ was relatively stable with respect to dissolved $\mathrm{Al}$.

In $\mathrm{Na}_{2} \mathrm{SO}_{4}$ equilibrated with $\mathrm{O}_{2}-0.1 \mathrm{SO}_{2}$ at $700{ }^{\circ} \mathrm{C}$, $\mathrm{NiO}$ undergoes acidic dissolution to form a liquid $\mathrm{NiSO}_{4}-\mathrm{Na}_{2} \mathrm{SO}_{4}$ solution [22]. As a consequence, the absence of significant $\mathrm{NiO}$ dissolution during the reaction of NiAl with $\mathrm{Na}_{2} \mathrm{SO}_{4}$ in $\mathrm{O}_{2}-0.1 \mathrm{SO}_{2}$ indicates that little $\mathrm{NiO}$ was formed. In other words, even though the alloy likely produced some transient $\mathrm{NiO}$, its dissolution was not rapid enough to disrupt the establishment of an external $\mathrm{Al}_{2} \mathrm{O}_{3}$ scale. Furthermore, wherever this scale lost its protective character and a nodule developed, a relatively low $p_{\mathrm{O}_{2}}$ was maintained at the nodule surface, such that the activity of $\mathrm{NiO}$ in the mixed oxide was too low for its acidic dissolution to proceed significantly. The observation that some porous $\mathrm{NiO}$ was present at the surface of the largest nodules indicates that as nodules developed, the oxide in their upper part tended to get enriched in $\mathrm{Ni}$, until eventually $\mathrm{NiO}$ could form and react with $\mathrm{Na}_{2} \mathrm{SO}_{4}$ - this segregation simply reflects the relative stabilities of $\mathrm{Al}$ and $\mathrm{Ni}$ oxide, as in the non-selective oxidation of dilute alloys.

During exposure to the liquid $\mathrm{Na}_{2} \mathrm{SO}_{4}-\mathrm{MgSO}_{4}$ in $\mathrm{O}_{2}-0.1 \mathrm{SO}_{2}$, local $\mathrm{Al}_{2} \mathrm{O}_{3}$ failure also resulted in internal oxidation (Figure 9a). The semi-continuous, deep corrosion product evolved from a localized type of attack. Indeed, longer exposure to $\mathrm{Na}_{2} \mathrm{SO}_{4}$ ( $100 \mathrm{~h}$, not shown here) eventually produced larger, semi-continuous nodules, suggesting that the liquid deposit simply accelerated the internal attack. As mentioned above, Ni segregation within the nodule eventually led to NiO formation and dissolution in the sulfate, but an important conclusion here is that the initial reaction process of $\mathrm{NiAl}$ exposed to a sulfate in mildly acidic conditions at $700^{\circ} \mathrm{C}$ is not one of hot corrosion. Rather, it is internal oxidation assisted by $\mathrm{S}$, even when the applied sulfate is liquid.

Now turning to air exposures, the continued presence of a thin $\mathrm{Al}_{2} \mathrm{O}_{3}$ scale after reaction with $\mathrm{Na}_{2} \mathrm{SO}_{4}-\mathrm{MgSO}_{4}$ indicates that the solubility of $\mathrm{Al}_{2} \mathrm{O}_{3}$ in the melt was low in these relatively basic conditions, in agreement with previous findings [38]. Some isolated nodules were formed (Figure 8b); their constitution (internal sulfides at the reaction front, aluminates towards the surface) is consistent with a process of basic fluxing, while the non- 
uniform reaction morphology points to local disruptions of the generally protective $\mathrm{Al}_{2} \mathrm{O}_{3}$ scale. In line with mechanistic descriptions of basic fluxing during type I hot corrosion [2], it is inferred that the protective regime is only maintained so long as sulfidation of the alloy by a locally oxygen-deprived melt is prevented: when the $\mathrm{Al}_{2} \mathrm{O}_{3}$ scale locally fails, sulfidation consumes $\mathrm{SO}_{3}$, and the increased basicity destabilizes $\mathrm{Al}$ and $\mathrm{Ni}$ oxides. Even then, the solubility of the aluminate and nickelate ions must have remained relatively low (or, rather, must have rapidly returned to a low level), as most intrusions reached 1-2 $\mu \mathrm{m}$ deep and repassivated, without forming larger nodules such as that shown in Figure 8b.

In the absence of $\mathrm{SO}_{3}$ in the gas, the $\mathrm{Na}_{2} \mathrm{SO}_{4}-\mathrm{MgSO}_{4}$ solution itself was relatively unstable, as indicated by the precipitation of $\mathrm{MgO}$ (the $p_{\mathrm{SO}_{3}}$ for $\mathrm{MgO} / \mathrm{MgSO}_{4}$ equilibrium, both taken as solid phases at unit activity, is calculated to be $2.2 \times 10^{-6}$ atm at $700{ }^{\circ} \mathrm{C}$ from data in Ref. [10], which is much higher than the $\mathrm{Na}_{2} \mathrm{O} / \mathrm{Na}_{2} \mathrm{SO}_{4}$ value of $6.6 \times 10^{-23} \mathrm{~atm}$, and apparently higher than was present in the air cylinder). Rahmel and coworkers $[40,41]$ previously discussed the consequences of the low stability of $\mathrm{MgSO}_{4}$, suggesting that the precipitation of a continuous $\mathrm{MgO}$ layer on the corrosion product would inhibit hot corrosion in basic conditions. This may have limited the size of the nodules observed here.

In light of these observations, the absence of nodules after reaction of $\mathrm{NiAl}$ with $\mathrm{Na}_{2} \mathrm{SO}_{4}$ alone in air is readily understood. Local breakdown of the $\mathrm{Al}_{2} \mathrm{O}_{3}$ scale resulted in 1-2 $\mu \mathrm{m}$ intrusions of $\mathrm{Al}$ oxide (Figure 8a), but in the absence of an extended liquid phase, basic fluxing did not proceed further. We conclude that NiAl may be subject to limited basic fluxing in air at $700{ }^{\circ} \mathrm{C}$, but this requires the continued presence of a liquid deposit.

\subsection{Reactivity of NiAlCr; effect of $\mathrm{Cr}$}

Starting with the relatively basic conditions, the absence of nodules or of any other sign of accelerated attack of $\mathrm{NiAlCr}$ after exposure to the liquid $\mathrm{Na}_{2} \mathrm{SO}_{4}-\mathrm{MgSO}_{4}$ deposit in air indicates that either the $\mathrm{Al}_{2} \mathrm{O}_{3}$ scale did not experience local failure, or that the solubilities of nickelate and aluminate ions in the liquid melt were negligibly small. Chromia readily dissolves in basic sulfate melts, which is known to increase the melt acidity and hamper the basic dissolution of $\mathrm{NiO}$ and $\mathrm{Al}_{2} \mathrm{O}_{3}$ [2]. This may possibly explain the absence of hot corrosion of NiAlCr in air.

The addition of $\mathrm{SO}_{3}$ in the gas caused a substantial change, as NiAlCr samples exposed to $\mathrm{Na}_{2} \mathrm{SO}_{4}$ and $\mathrm{Na}_{2} \mathrm{SO}_{4}-\mathrm{MgSO}_{4}$ deposits in $\mathrm{O}_{2}-0.1 \mathrm{SO}_{2}$ suffered uniform accelerated attack. After reaction, the $\mathrm{Na}_{2} \mathrm{SO}_{4}$ deposit contained significant amounts of $\mathrm{Al}, \mathrm{Cr}$ and $\mathrm{Ni}$, and a porous oxide developed at the sulfate/gas interface (Figure 7). Acidification of the sulfate by the gas apparently triggered a fluxing type reaction mechanism, which emphasizes the critical role played by salt chemistry (that is, in terms of its acidity; our results suggest that $\mathrm{MgSO}_{4}$ has no significant effect in acidic conditions, which is consistent with findings by Rahmel and coworkers $[40,41]$ from polarization studies at higher temperatures). Conversely, the fact that similar morphologies and extents of reaction were observed with the initially solid $\mathrm{Na}_{2} \mathrm{SO}_{4}$ and the liquid $\mathrm{Na}_{2} \mathrm{SO}_{4}-\mathrm{MgSO}_{4}$ deposits indicates that insofar as the ambient $p_{\mathrm{SO}_{3}}$ allows the formation of a liquid $\mathrm{Na}_{2} \mathrm{SO}_{4}-\mathrm{NiSO}_{4}$ solution, the initial state of the deposit (solid or liquid) is not decisive.

The critical question here is how the addition of 5 at. \% $\mathrm{Cr}$ to NiAl could trigger a fluxing-type mechanism that was absent for the binary alloy. This encompasses two issues, 
(i) the inability of the Cr-bearing alloy to establish a protective $\mathrm{Al}_{2} \mathrm{O}_{3}$ scale, and (ii) the tendency for $\mathrm{Al}, \mathrm{Cr}$ and $\mathrm{Ni}$ oxides to dissolve in the sulfate and precipitate at its surface. During oxidation in air with no deposit at $700{ }^{\circ} \mathrm{C}$, the NiAlCr alloy formed less transient $\mathrm{NiO}$ than NiAl did [26]. Yet this did not have the expected beneficial effect in the presence of a deposit, which, as will be argued now, is related to the influence of $\mathrm{Cr}$ on the sulfate chemistry.

As discussed in Section 4.1, the solubility of $\mathrm{Al}$ in $\mathrm{Na}_{2} \mathrm{SO}_{4}$ at $700{ }^{\circ} \mathrm{C}$ is not known, but it is estimated to be close to its minimum at the $p_{\mathrm{SO}_{3}}$ of interest, $7.1 \times 10^{-4} \mathrm{~atm}$. The case of $\mathrm{Cr}$ is similar: no data are available at $700{ }^{\circ} \mathrm{C}$, but measurements by Zhang [42] place the solubility minimum at $p_{\mathrm{SO}_{3}}=4 \times 10^{-2}$ atm at $927^{\circ} \mathrm{C}$, and considering the thermodynamics of the $\mathrm{Na}_{2} \mathrm{CrO}_{4} / \mathrm{Cr}_{2} \mathrm{O}_{3}$ and $\mathrm{Cr}_{2} \mathrm{O}_{3} / \mathrm{Cr}_{2}\left(\mathrm{SO}_{4}\right)_{3}$ equilibria, the solubility is thought to be close to its minimum in the present experimental conditions. (Since the degree of oxidation of $\mathrm{Cr}$ changes from + III in $\mathrm{Cr}_{2} \mathrm{O}_{3}$ to $+\mathrm{VI}$ in $\mathrm{CrO}_{4}^{2-}$, the solubility of chromate ions varies with $p_{\mathrm{O}_{2}}$; however, Zhang's measurements show that $\mathrm{CrO}_{2}^{-}$rapidly predominates in the basic regime as $p_{\mathrm{O}_{2}}$ decreases, and overall the influence of $p_{\mathrm{O}_{2}}$ on the minimum solubility is marginal, until $\mathrm{Cr}^{2+}(\underline{\mathrm{CrS}})$ is prevalent at a very low $p_{\mathrm{O}_{2}}$.) Hence the predominant solutes of $\mathrm{Al}$ and $\mathrm{Cr}$ are undetermined a priori, and will depend on local variations of the sulfate chemistry away from its equilibrium composition (i.e., that defined by the gas $p_{\mathrm{SO}_{3}}$ ). Since the consumption of $\mathrm{O}$ and $\mathrm{S}$ by reaction with the alloy tends to lower the $p_{\mathrm{SO}_{3}}$, basic dissolution appears more likely.

The simultaneous presence of $\mathrm{Al}, \mathrm{Cr}$ and $\mathrm{Ni}$ in the sulfate after reaction of $\mathrm{NiAlCr}$ in $\mathrm{O}_{2}$ $0.1 \mathrm{SO}_{2}$ is indicative of a coupled acid-base dissolution phenomenon. Acidic dissolution of $\mathrm{NiO}$ itself is relatively slow in the conditions of interest, in particular too slow to disrupt the establishment of $\mathrm{Al}_{2} \mathrm{O}_{3}$ on $\mathrm{NiAl}$. This is presumably due to slow $\mathrm{SO}_{3}$ transport $\left(\mathrm{as}_{2} \mathrm{O}_{7}^{2-}\right.$ ) in the sulfate, which would both limit the dissolution kinetics and lower its driving force. Indeed if mass transport is slow, acidic dissolution causes a local rise in basicity, and $\mathrm{Ni}^{2+}$ solubility is decreased. In the presence of $\mathrm{Cr}$, however, basic dissolution of $\mathrm{Cr}_{2} \mathrm{O}_{3}$ provides a local source of $\mathrm{SO}_{3}$, facilitating the acidic dissolution of $\mathrm{NiO}$ :

$$
\begin{aligned}
\mathrm{Cr}_{2} \mathrm{O}_{3}+2 \mathrm{SO}_{4}^{2-} & =2 \underline{\mathrm{CrO}_{2}^{-}}+\underline{\mathrm{S}_{2} \mathrm{O}_{7}^{2-}} \\
\mathrm{NiO}+\underline{\mathrm{S}_{2} \mathrm{O}_{7}^{2-}} & =\underline{\mathrm{Ni}^{2+}}+2 \underline{\mathrm{SO}_{4}^{2-}}
\end{aligned}
$$

The rapid exchange of ions would also allow the basic dissolution of $\mathrm{Al}_{2} \mathrm{O}_{3}$,

which otherwise is very slow, to proceed.

$$
\mathrm{Al}_{2} \mathrm{O}_{3}+2 \underline{\mathrm{SO}_{4}^{2-}}=2 \underline{\mathrm{AlO}_{2}^{-}}+\underline{\mathrm{S}_{2} \mathrm{O}_{7}^{2-}}
$$

This process of synergistic dissolution, in which the $\mathrm{SO}_{3}$ required for acidic dissolution of a basic oxide (here $\mathrm{NiO}$ ) is provided by the basic dissolution of a more acidic oxide $\left(\mathrm{Cr}_{2} \mathrm{O}_{3}, \mathrm{Al}_{2} \mathrm{O}_{3}\right)$, has been documented by previous investigators [4]. In particular, Hwang and Rapp [16] monitored the sulfate chemistry during individual and coupled dissolution of $\mathrm{Fe}_{2} \mathrm{O}_{3}$ and $\mathrm{Cr}_{2} \mathrm{O}_{3}$, and showed that coupled reactions were faster than individual ones. The authors noted that $\mathrm{Al}_{2} \mathrm{O}_{3}$ - or $\mathrm{Cr}_{2} \mathrm{O}_{3}$-forming alloys that failed to exclude transient oxidation of $\mathrm{Ni}$ or $\mathrm{Co}$ would be particularly susceptible to hot corrosion because of synergistic dissolution. Here, we propose that as a result of the local $\mathrm{SO}_{3}$ exchange, accelerated $\mathrm{NiO}$ dissolution in the presence of $\mathrm{Cr}_{2} \mathrm{O}_{3}$ prevented the establishment of an external $\mathrm{Al}_{2} \mathrm{O}_{3} \mathrm{Scale}_{\text {. }}$ This is plausible inasmuch as dissolution kinetics are controlled by ionic transport in the 
melt, which was verified in Ref. [16] in the case of $\mathrm{Cr}_{2} \mathrm{O}_{3}$ and $\mathrm{Fe}_{2} \mathrm{O}_{3}$. The dissolution process apparently overcame the ability of $\mathrm{Cr}$ to mitigate transient $\mathrm{NiO}$ formation.

The fact that a coupled dissolution process occurred in NiAlCr and not in $\mathrm{NiAl}$ suggests that the solubility of $\mathrm{CrO}_{4}^{2-}$ (or $\mathrm{CrO}_{2}^{-}$) is greater than that of $\mathrm{AlO}_{2}^{-}$in these mildly acidic conditions. Solubility measurements compiled in Ref. [4] indicate that this is indeed the case in the range of $p_{\mathrm{SO}_{3}}$ investigated at $927^{\circ} \mathrm{C}$. In electrochemical polarization studies at $900{ }^{\circ} \mathrm{C}$, Fukumoto et al. [43] also reported this trend in a central potential range, but the solubility of $\mathrm{Al}$ reached much higher values at very anodic and very cathodic potentials. Solubility data at $700{ }^{\circ} \mathrm{C}$ would be very useful here to facilitate a more detailed discussion.

In order to test, qualitatively, the proposed interpretation, specimens of NiAl were exposed to mixed $\mathrm{Na}_{2} \mathrm{SO}_{4}-\mathrm{xCr}_{2} \mathrm{O}_{3}$ deposits ( $\mathrm{x}=5 \times 10^{-3}, 5 \times 10^{-2}$ and $0.5 \mathrm{~mol} \%$ ) in $\mathrm{O}_{2}-0.1 \mathrm{SO}_{2}$. Basic dissolution of $\mathrm{Cr}_{2} \mathrm{O}_{3}$ in molten $\mathrm{Na}_{2} \mathrm{SO}_{4}$ equilibrated with $\mathrm{O}_{2}-\mathrm{SO}_{2}$ at $927{ }^{\circ} \mathrm{C}$ was measured in Ref. [16] to be rather slow, reaching $50 \%$ of saturation in about $10 \mathrm{~h}$, and should be even slower if not negligible in solid $\mathrm{Na}_{2} \mathrm{SO}_{4}$ at $700{ }^{\circ} \mathrm{C}$. Thus dissolution is mainly expected to occur if and where a liquid $\mathrm{Na}_{2} \mathrm{SO}_{4}-\mathrm{NiSO}_{4}$ solution is formed by reaction with the alloy.

With $5 \times 10^{-3} \% \mathrm{Cr}_{2} \mathrm{O}_{3}$ added to the $\mathrm{Na}_{2} \mathrm{SO}_{4}$, nodules of internal Al-rich oxide developed, with the same morphology as those found after exposure to pure $\mathrm{Na}_{2} \mathrm{SO}_{4}$. However, these covered almost the entire alloy surface, and porous $\mathrm{NiO}$ was present on most of the nodules, including small ones (Figure 11a). With $5 \times 10^{-2} \% \mathrm{Cr}_{2} \mathrm{O}_{3}$, nodules covered the whole surface, while at $0.5 \%$ the corrosion product had turned into a semi-continuous scale of Al-rich oxide, with a porous $\mathrm{NiO}$ layer at its surface, and internal sulfides ahead of the oxidation front (Figure 11b). While deposits were only applied to the flat surfaces, the sides of the specimens exposed to the $\mathrm{Na}_{2} \mathrm{SO}_{4}-\mathrm{Cr}_{2} \mathrm{O}_{3}$ mixtures were heavily corroded, which suggests that a liquid sulfate had formed. This was not the case for the pure $\mathrm{Na}_{2} \mathrm{SO}_{4}$ deposit.

The higher nodule densities observed with $\mathrm{Na}_{2} \mathrm{SO}_{4}-\mathrm{Cr}_{2} \mathrm{O}_{3}$ mixtures are indicative of nucleation events being more frequent: defects naturally occurring in the growing $\mathrm{Al}_{2} \mathrm{O}_{3}$ scale were more likely to lead to local breakdown and internal oxidation in the presence of $\mathrm{Cr}_{2} \mathrm{O}_{3}$. This result is consistent with the proposed interpretation of the effect of alloying $\mathrm{NiAl}$ with $\mathrm{Cr}$. Specifically, the dissolution of $\mathrm{Cr}_{2} \mathrm{O}_{3}$ enhances the dissolution of $\mathrm{NiO}$ and $\mathrm{Al}_{2} \mathrm{O}_{3}$, likely through a process of acid-base coupling, which prevents effective alloy passivation (or repassivation).

In analyzing the effects of the gas and sulfate chemistry on the stability of thermally grown oxides, it is useful to consider two limiting situations. If mass transport in the sulfate were very rapid compared to dissolution reactions, the gas phase conditions $\left(p_{\mathrm{O}_{2}}, p_{\mathrm{SO}_{3}}\right)$ would prevail everywhere in the sulfate, regardless of dissolution reactions, which would proceed independently from each other. If, on the other hand, mass transport were very slow, the sulfate chemistry near the oxide/sulfate interface, initially set by equilibrium with the gas, would be affected by dissolution reactions, and acid-base coupling would be significant. In this latter case, the chemistry of sulfate solutions may be conveniently analyzed in a manner analogous to that of aqueous solutions. Consider for example the individual dissolution of $\mathrm{Cr}_{2} \mathrm{O}_{3}$. In a relatively acidic sulfate, the solubility of $\mathrm{CrO}_{2}^{-}$is small, $\mathrm{Cr}_{2} \mathrm{O}_{3}$ does not dissolve significantly, and the ambient $p_{\mathrm{SO}_{3}}$ is not affected. In a more basic sulfate however, a larger amount of $\mathrm{CrO}_{2}^{-}$is produced, which leads to a local increase of $p_{\mathrm{SO}_{3}}$ until an equilibrium is reached. In this case, the $\mathrm{Cr}_{2} \mathrm{O}_{3} / \mathrm{CrO}_{2}^{-}$couple acts as a buffer for the 
$p_{\mathrm{SO}_{3}}$, in the same way as large concentrations of an acid and its conjugate base buffer the $\mathrm{pH}$ of an aqueous solution. The analysis is developed in detail in the Appendix. In particular, we show that in a certain range of initial sulfate compositions, the coupled dissolution of $\mathrm{Cr}_{2} \mathrm{O}_{3}$ and $\mathrm{NiO}$ would locally buffer a $p_{\mathrm{SO}_{3}}$ intermediate between those individually established by the $\mathrm{Cr}_{2} \mathrm{O}_{3} / \mathrm{CrO}_{2}^{-}$and $\mathrm{NiO} / \mathrm{Ni}^{2+}$ couples. This buffered $p_{\mathrm{SO}_{3}}$ is determined by the equilibrium constants of the dissolution reactions, and is independent of the starting $p_{\mathrm{SO}_{3}}$. In other words, in this regime, oxide solubilities are independent of the gas composition.

A NiAl specimen was reacted with $\mathrm{Na}_{2} \mathrm{SO}_{4}-5 \% \mathrm{Cr}_{2} \mathrm{O}_{3}$ in air and no accelerated corrosion of any sort was observed. Similarly, no hot corrosion occurred when NiAlCr was exposed to $\mathrm{Na}_{2} \mathrm{SO}_{4}$ or even $\mathrm{Na}_{2} \mathrm{SO}_{4}-\mathrm{MgSO}_{4}$ in air. Thus local equilibria in air and in $\mathrm{O}_{2}-0.1 \mathrm{SO}_{2}$ did not in fact buffer the same $p_{\mathrm{SO}_{3}}$. However, the presence of $\mathrm{Cr}_{2} \mathrm{O}_{3}$ did have a significant effect on tests conducted in $\mathrm{O}_{2}-0.1 \mathrm{SO}_{2}$. The apparent contradiction is most likely due to the complex interplay between the reaction kinetics on the one hand, and the chemistry, physical state (solid vs liquid) and transport properties of the sulfate on the other hand. We conclude that mass transport proceeded at an intermediate rate, allowing both the gas composition and the dissolution reactions to affect the sulfate chemistry. It is noted that in Hwang and Rapp's synergistic dissolution experiments [16], the salt $p_{\mathrm{SO}_{3}}$ was not significantly affected by $\mathrm{Cr}_{2} \mathrm{O}_{3}$ dissolution, whether individual or coupled with that of $\mathrm{Fe}_{2} \mathrm{O}_{3}$. Instead coupled dissolution kinetics were controlled by the $\mathrm{Fe}_{2} \mathrm{O}_{3}$ reaction, and the salt $p_{\mathrm{SO}_{3}}$ by the $\mathrm{Fe}_{2} \mathrm{O}_{3} / \mathrm{Fe}^{3+}, \mathrm{Fe}^{2+}$ equilibrium, until no oxide was left and it returned to the value set by the gas. The key aspect is that $\mathrm{Cr}_{2} \mathrm{O}_{3}$ may not be acidic enough to establish high $p_{\mathrm{SO}_{3}}$ levels, sufficient to trigger $\mathrm{NiO}$ dissolution for example, but $\mathrm{Cr}_{2} \mathrm{O}_{3}$ dissolution will allow a shortrange exchange of $\mathrm{SO}_{3}$ which will facilitate $\mathrm{NiO}$ dissolution so long as the ambient $p_{\mathrm{SO}_{3}}$ is acidic with respect to $\mathrm{NiO}$. Thus, the effect of $\mathrm{Cr}$ is primarily kinetic in nature, but has the consequence of changing the mode of attack.

\subsection{Comments on the effect of $\mathrm{Cr}$}

Chromium has been widely recognized as very beneficial to resistance against hot corrosion. For example, Goward suggested in a 1986 review of protective coatings [44] that $15-20 \% \mathrm{Cr}$ were required for protection in type II conditions, and works reviewed in Ref. [5] showed that 30-35\% Cr offered yet superior resistance. Several studies of cyclic, type I hot corrosion of $\mathrm{Ni}$ aluminides [45-47] showed that small $\mathrm{Cr}$ additions were beneficial, more so than Pt additions for example. An extensive study of NiCrAl alloys at $900-1100{ }^{\circ} \mathrm{C}$ [48] also showed a beneficial effect of $\mathrm{Cr}$ in the $\beta-\gamma$ region. In this context, the observation reported here that $\mathrm{Cr}$ triggers a fluxing-type mechanism, which is typically associated with high corrosion rates, may seem unsettling at first. However, the results mentioned above concern either increased $\mathrm{Cr}$ levels in MCrAlY alloys already containing $\mathrm{Cr}$, or type I conditions, or both, whereas the present work concerns small $\mathrm{Cr}$ additions to $\mathrm{Cr}$-free $\mathrm{NiAl}$ in type II conditions. As will be argued here, the apparent variance resides in the fact that hot corrosion in various conditions of temperature and alloy and gas composition involves distinct mechanisms, which are differently affected by the $\mathrm{Cr}$ concentration. 
It is first noted that direct comparisons between short term, isothermal exposures discussed here and long term, cyclic tests (e.g. Ref. [47]) or even burner rig tests (e.g. Ref. [46]) should be made with caution. Indeed, alloy performances in thermal cycling are influenced by their resistance to spallation and their inherent ability to re-form protective $\mathrm{Al}_{2} \mathrm{O}_{3}$ scales (which benefits from $\mathrm{Cr}$ additions) as much as by the reaction with the sulfate deposit. The sulfate chemistry may vary during the test and go through successive steadystates as the deposit interacts with the sample, is removed because of evaporation or scale spallation, and is re-applied. This obviously makes mechanistic analyses extremely challenging.

Perhaps the best understood aspect of alloying with $\mathrm{Cr}$ is that the basic dissolution of $\mathrm{Cr}_{2} \mathrm{O}_{3}$ to form chromate ions (or chromite, depending on the local $p_{\mathrm{O}_{2}}$ [42]) reduces the melt basicity to a level where basic dissolution of $\mathrm{NiO}$ or $\mathrm{Al}_{2} \mathrm{O}_{3}$ is avoided [2]. This is mostly relevant to type I conditions, where basic fluxing is a problem. Although $\mathrm{Cr}_{2} \mathrm{O}_{3}$ is acidic like oxides of other refractory metals such as $\mathrm{W}$ or $\mathrm{Mo}$, the formation of $\mathrm{CrO}_{2}^{-}$will not by itself induce acidic dissolution of $\mathrm{Al}_{2} \mathrm{O}_{3}$, whereas that of $\mathrm{WO}_{4}^{2-}$ or $\mathrm{MoO}_{4}^{2-}$ will [2]. Thus the $\mathrm{Cr}_{2} \mathrm{O}_{3} / \mathrm{CrO}_{2}^{-}$couple tends to buffer the melt in a region of $\mathrm{NiO}$ and $\mathrm{Al}_{2} \mathrm{O}_{3}$ stability, hampering basic fluxing but not causing alloy-induced acidic fluxing in basic environments.

For alloys with high $\mathrm{Cr}$ contents but little or no $\mathrm{Al}$, which rely on $\mathrm{Cr}_{2} \mathrm{O}_{3}$ for corrosion resistance, increasing the $\mathrm{Cr}$ concentration will reduce the extent of transient oxidation, i.e., the amount of $\mathrm{Ni}$ or $\mathrm{Co}$ oxide exposed to $\mathrm{Na}_{2} \mathrm{SO}_{4}$. In this case higher $\mathrm{Cr}$ contents are very beneficial, particularly in type II conditions as observed by Luthra [49] in the Co-Cr system. In electrochemical polarization studies, Fukumoto et al. [43] found that the solubility of $\mathrm{Al}_{2} \mathrm{O}_{3}$ became much greater than that of $\mathrm{Cr}_{2} \mathrm{O}_{3}$ at very low and very high potentials. This is to be related with the earlier work by $\mathrm{Wu}$ et al. [50], who showed that the breakdown potential (past which oxide dissolution and rapid corrosion occur) of $\mathrm{Cr}_{2} \mathrm{O}_{3}$ was more negative than that of $\mathrm{Al}_{2} \mathrm{O}_{3}$ in basic conditions, and more positive in acidic conditions, i.e., the passive range of $\mathrm{Cr}_{2} \mathrm{O}_{3}$ was wider. The authors linked this to the superior resistance of commercial $\mathrm{Cr}_{2} \mathrm{O}_{3}$-forming alloys over $\mathrm{Al}_{2} \mathrm{O}_{3}$-forming alloys. Furthermore, as argued by Luthra [49] and Rapp [4], the fact that solid-state diffusion is much faster in $\mathrm{Cr}_{2} \mathrm{O}_{3}$ than in $\mathrm{Al}_{2} \mathrm{O}_{3}$ may be an advantage for hot corrosion resistance, as a continuous scale would be established more rapidly, more effectively preventing exposure of the base metal. This is thought to be particularly significant at $600-800{ }^{\circ} \mathrm{C}$, where transient oxidation is more important on $\mathrm{Al}_{2} \mathrm{O}_{3}$-formers than on $\mathrm{Cr}_{2} \mathrm{O}_{3}$-formers [51]. Both the more rapid growth and the wider passive range explain why increasing the $\mathrm{Cr}$ content of a marginal $\mathrm{Al}_{2} \mathrm{O}_{3}$-former, switching to $\mathrm{Cr}_{2} \mathrm{O}_{3}$ formation, can be beneficial. The cases of $\mathrm{Cr}_{2} \mathrm{O}_{3}$-formers or marginal $\mathrm{Al}_{2} \mathrm{O}_{3}$ formers are very different from the present situation, where $\mathrm{Cr}$ was added to $\mathrm{NiAl}$ in a small quantity, and the alloy remained an $\mathrm{Al}_{2} \mathrm{O}_{3}$-former.

Finally, it is noted that while producing $\mathrm{Cr}$-free diffusion coatings is impractical because most substrates would contain $\mathrm{Cr}$, it is not necessarily desirable. As mentioned earlier, the types of attack observed on $\mathrm{NiAl}$ and NiAlCr were very different in nature, and also in terms of kinetics, such that longer term $(100 \mathrm{~h})$ exposure led to locally deeper metal loss for the binary alloy than for NiAlCr. Since local failure of a protective scale can hardly be avoided during service, $\mathrm{Cr}$ may provide some degree of protection on the long term, even in type II conditions. 


\section{Conclusions}

The short term exposure of $\mathrm{NiAl}$ and $\mathrm{NiAlCr}$ to $\mathrm{Na}_{2} \mathrm{SO}_{4}$ in $\mathrm{O}_{2}-0.1 \mathrm{SO}_{2}$ at $700{ }^{\circ} \mathrm{C}$ produced two distinct reaction morphologies, resulting from distinct mechanisms. The NiAl alloy was able to form an external $\mathrm{Al}_{2} \mathrm{O}_{3}$ scale, but local scale failure led to internal oxidation and rapid nodule development. Both the nucleation of $\mathrm{Al}_{2} \mathrm{O}_{3}$ intrusions and the subsequent propagation of the internal oxidation front were associated with the presence of $\mathrm{S}$ at the metal/oxide interface. The reaction mechanism did not involve significant oxide dissolution in the sulfate. In particular, the $\mathrm{Al}_{2} \mathrm{O}_{3}$ remained chemically stable even when a liquid $\mathrm{Na}_{2} \mathrm{SO}_{4}-\mathrm{MgSO}_{4}$ deposit was used. Nevertheless, scale failure and nodule development did require the presence of an acidified sulfate deposit.

The addition of $\mathrm{Cr}$ to the alloy led to a uniform type of attack where $\mathrm{NiO}$ and $\mathrm{Al}_{2} \mathrm{O}_{3}$ dissolved significantly in the sulfate, a porous, non-protective scale formed, and the alloy was internally sulfidized. A similar reaction morphology was observed when a $\mathrm{Na}_{2} \mathrm{SO}_{4}$ $\mathrm{MgSO}_{4}$ deposit was used, but not when the reaction was conducted in air, with either of the deposits. Furthermore, the addition of $\mathrm{Cr}_{2} \mathrm{O}_{3}$ to $\mathrm{Na}_{2} \mathrm{SO}_{4}$ enhanced nodule development on $\mathrm{NiAl}$ in $\mathrm{O}_{2}-0.1 \mathrm{SO}_{2}$. These results were analyzed by considering the role of the gas composition and of the dissolution reactions on the sulfate chemistry. The acidic dissolution of $\mathrm{NiO}$ is made thermodynamically possible by the acidification of the sulfate through equilibrium with the gas phase. This occurs independently of whether the applied sulfate is solid or liquid. While selective oxidation initially protects the binary alloy, the dissolution of $\mathrm{Cr}_{2} \mathrm{O}_{3}$ at the surface of the $\mathrm{NiAlCr}$ alloy causes a rapid local exchange of $\mathrm{SO}_{3}$, which allows $\mathrm{NiO}$ dissolution to proceed more rapidly than an external $\mathrm{Al}_{2} \mathrm{O}_{3}$ scale can establish.

\section{Acknowledgements}

This work was supported by the Department of Energy through the University Turbine Systems Research Program run by the National Energy Technology Laboratory, award number DE-FE0007271, Dr. Seth Lawson, project manager, and by the Office of Naval Research under grant N00014-11-1-0605, Dr. David Shifler, program manager. The authors thank Profs. G.H. Meier and D. Waldeck at the University of Pittsburgh for useful discussions.

\section{Appendix}

The dissolution of oxides in $\mathrm{Na}_{2} \mathrm{SO}_{4}$ is studied here by analogy with acid-base equilibria in aqueous solutions. We consider a situation where transport in the sulfate is slow, to the extent that the sulfate chemistry at the oxide/sulfate interface is locally controlled by the equilibria associated with oxide dissolution. Three cases are studied: independent dissolution of acidic and basic oxides, and coupled dissolution.

\subsection{Independent dissolution of an acidic oxide}


Let $\mathrm{AO}$ be an acidic oxide, which reacts to produce $\mathrm{Na}_{2} \mathrm{AO}_{2}$ in solution in $\mathrm{Na}_{2} \mathrm{SO}_{4}$. Initially, the sulfate does not contain any $\mathrm{Na}_{2} \mathrm{AO}_{2}$, and its $p_{\mathrm{SO}_{3}}$ is set through equilibrium with the gas. The equilibrium $\mathrm{Na}_{2} \mathrm{AO}_{2}$ activity as a function of the initial $p_{\mathrm{SO}_{3}}$ is calculated by considering the following mass balances:

\begin{tabular}{|c|c|c|c|c|c|}
\hline $\begin{array}{l}\text { initial } \\
\text { equilibrium }\end{array}$ & $\begin{array}{c}\mathrm{AO} \\
n_{\mathrm{AO}}^{i} \\
n_{\mathrm{AO}}^{i}-x\end{array}$ & + & $\begin{array}{c}\mathrm{Na}_{2} \mathrm{O} \\
n_{\mathrm{Na}_{2} \mathrm{O}}^{i} \\
n_{\mathrm{Na}_{2} \mathrm{O}}^{i}-x\end{array}$ & $=$ & $\begin{array}{c}\mathrm{Na}_{2} \mathrm{AO}_{2} \\
0\end{array}$ \\
\hline $\begin{array}{l}\text { initial } \\
\text { equilibrium }\end{array}$ & $\begin{array}{c}\mathrm{Na}_{2} \mathrm{SO}_{4} \\
n_{\mathrm{Na}_{2} \mathrm{SO}_{4}}^{i} \\
n_{\mathrm{Na}_{2} \mathrm{SO}_{4}}^{i}\end{array}$ & $=$ & $\begin{array}{c}\mathrm{Na}_{2} \mathrm{O} \\
n_{\mathrm{Na}_{2} \mathrm{O}}^{i} \\
n_{\mathrm{Na}_{2} \mathrm{O}}^{i}+z\end{array}$ & + & $\begin{array}{c}\mathrm{SO}_{3} \\
n_{\mathrm{SO}_{3}}^{i} \\
n_{\mathrm{SO}_{3}}^{i}+z\end{array}$ \\
\hline
\end{tabular}

where $n_{j}^{i}$ is the initial amount of substance $j$ in a given unit volume, and $x$ and $z$ are the extents of reactions (A1) and (A2), respectively. The equilibrium constants associated with reactions (A1) and (A2) are defined as:

and

$$
K_{A}=\frac{a_{\mathrm{Na}_{2} \mathrm{AO}_{2}}}{a_{\mathrm{Na}_{2} \mathrm{O}}}
$$

$$
K=a_{\mathrm{Na}_{2} \mathrm{O}} \cdot p_{\mathrm{SO}_{3}}
$$

where the activities of the solid oxide $\mathrm{AO}$ and the solvent $\mathrm{Na}_{2} \mathrm{SO}_{4}$ are set to unity. The quantity of $\mathrm{Na}_{2} \mathrm{SO}_{4}$ is assumed constant and much larger than that of all other species. Thus the total number of moles in the unit volume is approximately constant, and concentrations equal number of moles directly obtained from the mass balances. For example, since $\mathrm{Na}_{2} \mathrm{O}$ is consumed by reaction (A1) and produced by reaction (A2), the equilibrium $\mathrm{Na}_{2} \mathrm{O}$ concentration is $C_{\mathrm{Na}_{2} \mathrm{O}}=n_{\mathrm{Na}_{2} \mathrm{O}}^{i}-x+z$. Activity coefficients are further assumed to be constant and equal to one for all species, such that activities are equated with concentrations. We obtain the following system:

which is solved to yield:

$$
\begin{gathered}
K_{A}=\frac{x}{a_{\mathrm{Na}_{2} \mathrm{O}}^{i}-x+z} \\
K=\left(a_{\mathrm{Na}_{2} \mathrm{O}}^{i}-x+z\right) \cdot\left(p_{\mathrm{SO}_{3}}^{i}+z\right)
\end{gathered}
$$

$$
\begin{gathered}
x=\frac{K_{A}}{2\left(1+K_{A}\right)}\left(\alpha+\frac{K}{p_{\mathrm{SO}_{3}}^{i}}-p_{\mathrm{SO}_{3}}^{i}\right) \\
z=\frac{1}{2}\left(\alpha-\frac{K}{p_{\mathrm{SO}_{3}}^{i}}-p_{\mathrm{SO}_{3}}^{i}\right)
\end{gathered}
$$

where $\alpha=\sqrt{\left(\frac{K}{p_{\mathrm{SO}_{3}}^{i}}-p_{\mathrm{SO}_{3}}^{i}\right)^{2}+4 K\left(1+K_{A}\right)}$, and the relationship $K=a_{\mathrm{Na}_{2} \mathrm{O}}^{i} \cdot p_{\mathrm{SO}_{3}}^{i}$ has been used assuming equilibrium in the sulfate prior to AO dissolution. The equilibrium activities $a_{\mathrm{Na}_{2} \mathrm{AO}_{2}}=x$ and $p_{\mathrm{SO}_{3}}=p_{\mathrm{SO}_{3}}^{i}+z$ are plotted as a function of $p_{\mathrm{SO}_{3}}^{i}$ in Figure A1. 
Three distinct regimes are identified. For $p_{\mathrm{SO}_{3}}^{i} \gg 2 \sqrt{K_{A} K}$ (regime R1), $\alpha$ can be approximated as $\alpha=p_{\mathrm{SO}_{3}}^{i}$, which yields $z=0$, and $p_{\mathrm{SO}_{3}}=p_{\mathrm{SO}_{3}}^{i}$. Using Eqs. (A3) and (A4), we find $a_{\mathrm{Na}_{2} \mathrm{AO}_{2}}=\frac{K_{A} K}{p_{\mathrm{SO}_{3}}^{i}}$. In this acidic regime, the solubility of $\mathrm{AO}$ is small. Thus reaction (A1) does not proceed significantly to the right, little $\mathrm{Na}_{2} \mathrm{AO}_{2}$ is produced and the ambient $p_{\mathrm{SO}_{3}}$ is not affected.

For $\frac{1}{2} \sqrt{\frac{K}{K_{A}}} \ll p_{\mathrm{SO}_{3}}^{i} \ll 2 \sqrt{K_{A} K}$ (regime R2), $\alpha$ is approximated as $\alpha=2 \sqrt{K_{A} K}$, which yields $a_{\mathrm{Na}_{2} \mathrm{AO}_{2}}=p_{\mathrm{SO}_{3}}=\sqrt{K_{A} K}$. In this intermediate regime, $a_{\mathrm{Na}_{2} \mathrm{AO}_{2}}$ and $p_{\mathrm{SO}_{3}}$ are independent of the initial $p_{\mathrm{SO}_{3}}$. Any small variation away from the equilibrium $p_{\mathrm{SO}_{3}}$ will be compensated by $\mathrm{AO}$ dissolution or precipitation. In other words, the $\mathrm{AO} / \mathrm{Na}_{2} \mathrm{AO}_{2}$ couple forms a buffer for $p_{\mathrm{SO}_{3}}$.

For $p_{\mathrm{SO}_{3}}^{i} \ll \frac{1}{2} \sqrt{\frac{K}{K_{A}}}$ (regime R3), $\alpha$ is approximated as $\alpha=\frac{K}{p_{\mathrm{SO}_{3}}^{i}}$, which yields $x=$ $\frac{K_{A} \cdot K}{\left(1+K_{A}\right) p_{\mathrm{SO}_{3}}^{i}}$. Since for common oxides $K_{A} \gg 1$, this results in $a_{\mathrm{Na}_{2} \mathrm{AO}_{2}}=\frac{K}{p_{\mathrm{SO}_{3}}^{i}}$. Using Eqs. (A3) and (A4), we obtain $p_{\mathrm{SO}_{3}}=K_{\mathrm{A}} \cdot p_{\mathrm{SO}_{3}}^{i}$. In this basic regime, the large excess of $\mathrm{Na}_{2} \mathrm{O}$ cannot be compensated by AO dissolution.

\subsection{Independent dissolution of a basic oxide}

Let $\mathrm{BO}$ be a basic oxide, which reacts to produce $\mathrm{BSO}_{4}$ in solution in $\mathrm{Na}_{2} \mathrm{SO}_{4}$. The equilibrium $\mathrm{BSO}_{4}$ is calculated by considering the following mass balance:

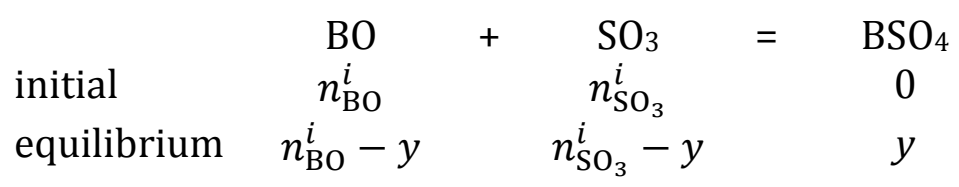

and the solvent dissociation equilibrium, reaction (A2). We use the same notations and assumptions adopted in Section 7.1. The equilibrium constant associated with reaction (A9) is defined as:

$$
K_{B}=\frac{a_{\mathrm{BSO}_{4}}}{p_{\mathrm{SO}_{3}}}
$$

where again the activity of the solid oxide BO is set to unity. We obtain the following system:

which is solved to yield:

$$
\begin{gathered}
K_{B}=\frac{y}{p_{\mathrm{SO}_{3}}^{i}-y+z} \\
K=\left(a_{\mathrm{Na}_{2} \mathrm{O}}^{i}+z\right) \cdot\left(p_{\mathrm{SO}_{3}}^{i}-y+z\right)
\end{gathered}
$$

$$
\begin{gathered}
y=\frac{K_{B}}{2\left(1+K_{B}\right)}\left(\beta-\frac{K}{p_{\mathrm{SO}_{3}}^{i}}+p_{\mathrm{SO}_{3}}^{i}\right) \\
z=\frac{1}{2}\left(\beta-\frac{K}{p_{\mathrm{SO}_{3}}^{i}}-p_{\mathrm{SO}_{3}}^{i}\right)
\end{gathered}
$$


where $\beta=\sqrt{\left(\frac{K}{p_{\mathrm{SO}_{3}}^{i}}-p_{\mathrm{SO}_{3}}^{i}\right)^{2}+4 K\left(1+K_{B}\right)}$. The equilibrium activities of $\mathrm{BSO}_{4}$ and $\mathrm{SO}_{3}$, obtained as $a_{\mathrm{BSO}_{4}}=y$ and $p_{\mathrm{SO}_{3}}=p_{\mathrm{SO}_{3}}^{i}-y+z$, are plotted as a function of $p_{\mathrm{SO}_{3}}^{i}$ in Figure A2.

Again three distinct regimes are identified. For $p_{\mathrm{SO}_{3}}^{i} \ll \frac{1}{2} \sqrt{\frac{K}{K_{B}}}$ (regime R1), equilibrium activities can be approximated as $p_{\mathrm{SO}_{3}}=p_{\mathrm{SO}_{3}}^{i}$ and $a_{\mathrm{BSO}_{4}}=K_{B} \cdot p_{\mathrm{SO}_{3}}^{i}$. In this basic regime, the solubility of $\mathrm{BO}$ is small. Thus reaction (A9) does not proceed significantly to the right, little $\mathrm{BSO}_{4}$ is produced and the ambient $p_{\mathrm{SO}_{3}}$ is not affected.

For $\frac{1}{2} \sqrt{\frac{K}{K_{B}}} \ll p_{\mathrm{SO}_{3}}^{i} \ll 2 \sqrt{K_{B} K}$ (regime R2), we obtain $a_{\mathrm{BSO}_{4}}=\sqrt{K_{B} K}$ and $p_{\mathrm{SO}_{3}}=\sqrt{\frac{K}{K_{B}}}$. In this intermediate regime, $a_{\mathrm{BSO}_{4}}$ and $p_{\mathrm{SO}_{3}}$ are independent of the initial $p_{\mathrm{SO}_{3}}$. The BO/BSO 4 couple forms a buffer for $p_{\mathrm{SO}_{3}}$.

For $p_{\mathrm{SO}_{3}}^{i} \gg 2 \sqrt{K_{B} K}$, (regime R3), we obtain $a_{\mathrm{BSO}_{4}}=p_{\mathrm{SO}_{3}}^{i}$ and $p_{\mathrm{SO}_{3}}=\frac{p_{\mathrm{SO}_{3}}^{i}}{K_{B}}$. In this acidic regime, the large excess of $\mathrm{SO}_{3}$ cannot be compensated by $\mathrm{BO}$ dissolution.

\subsection{Coupled dissolution of an acidic and a basic oxide}

We now consider the simultaneous dissolution of $\mathrm{AO}$ and $\mathrm{BO}$ in $\mathrm{Na}_{2} \mathrm{SO}_{4}$. The equilibrium activities are calculated by considering the mass balances associated with reactions (A1), (A2) and (A9). We obtain the following system:

$$
\begin{gathered}
K_{A}=\frac{x}{a_{\mathrm{Na}_{2} \mathrm{O}}^{i}-x+z} \\
K_{B}=\frac{y}{p_{\mathrm{SO}_{3}}^{i}-y+z} \\
K=\left(a_{\mathrm{Na}_{2} \mathrm{O}}^{i}-x+z\right) \cdot\left(p_{\mathrm{SO}_{3}}^{i}-y+z\right)
\end{gathered}
$$

which is solved to yield:

$$
\begin{gathered}
x=\frac{K_{A}}{2\left(1+K_{A}\right)}\left(\gamma+\frac{K}{p_{\mathrm{SO}_{3}}^{i}}-p_{\mathrm{SO}_{3}}^{i}\right) \\
y=\frac{K_{B}}{2\left(1+K_{B}\right)}\left(\gamma-\frac{K}{p_{\mathrm{SO}_{3}}^{i}}+p_{\mathrm{SO}_{3}}^{i}\right) \\
z=\frac{1}{2}\left(\gamma-\frac{K}{p_{\mathrm{SO}_{3}}^{i}}-p_{\mathrm{SO}_{3}}^{i}\right)
\end{gathered}
$$

where $\gamma=\sqrt{\left(\frac{K}{p_{\mathrm{SO}_{3}}^{i}}-p_{\mathrm{SO}_{3}}^{i}\right)^{2}+4 K\left(1+K_{A}+K_{B}+K_{A} K_{B}\right)}$. The equilibrium activities of $\mathrm{Na}_{2} \mathrm{AO}_{2}, \mathrm{BSO}_{4}$ and $\mathrm{SO}_{3}$ are plotted as a function of $p_{\mathrm{SO}_{3}}^{i}$ in Figure $\mathrm{A} 3$.

Again three distinct regimes are identified. For $p_{\mathrm{SO}_{3}}^{i} \ll \frac{1}{2} \sqrt{\frac{K}{K_{A} K_{B}}}$ (regime R1), equilibrium activities can be approximated as $a_{\mathrm{Na}_{2} \mathrm{AO}_{2}}=\frac{K}{p_{\mathrm{SO}_{3}}^{i}}, p_{\mathrm{SO}_{3}}=K_{A} \cdot p_{\mathrm{SO}_{3}}^{i}$ and $a_{\mathrm{BSO}_{4}}=K_{A} K_{B} \cdot p_{\mathrm{SO}_{3}}^{i}$. In 
this basic regime, little $\mathrm{BSO}_{4}$ is produced and the large excess of $\mathrm{Na}_{2} \mathrm{O}$ cannot be compensated by $\mathrm{AO}$ dissolution.

For $\frac{1}{2} \sqrt{\frac{K}{K_{A} K_{B}}} \ll p_{\mathrm{SO}_{3}}^{i} \ll 2 \sqrt{K_{A} K_{B} K}$ (regime R2), we obtain $a_{\mathrm{Na}_{2} \mathrm{AO}_{2}}=a_{\mathrm{BSO}_{4}}=\sqrt{K_{A} K_{B} K}$ and $p_{\mathrm{SO}_{3}}=\sqrt{\frac{K_{A} K}{K_{B}}}$. In this intermediate regime, all equilibrium activities are independent of the initial $p_{\mathrm{SO}_{3}}$. The $\mathrm{AO} / \mathrm{Na}_{2} \mathrm{AO}_{2} / \mathrm{BO} / \mathrm{BSO}_{4}$ quadruplet forms a buffer for $p_{\mathrm{SO}_{3}}$. It is noted that the range of the buffered regime is larger than those of the regimes buffered by individual dissolution of $\mathrm{AO}$ or $\mathrm{BO}$.

For $p_{\mathrm{SO}_{3}}^{i} \gg 2 \sqrt{K_{A} K_{B} K}$, (regime R3), we obtain $a_{\mathrm{Na}_{2} \mathrm{AO}_{2}}=\frac{K_{A} K_{B} K}{p_{\mathrm{SO}_{3}}^{i}}, p_{\mathrm{SO}_{3}}=\frac{p_{\mathrm{SO}_{3}}^{i}}{K_{B}}$ and $a_{\mathrm{BSO}_{4}}=$ $p_{\mathrm{SO}_{3}}^{i}$. In this acidic regime, little $\mathrm{Na}_{2} \mathrm{AO}_{2}$ is produced and the large excess of $\mathrm{SO}_{3}$ cannot be compensated by $\mathrm{BO}$ dissolution.

\section{References}

[1] M.A. DeCrescente, N.S. Bornstein, Formation and reactivity thermodynamics of sodium sulfate with gas turbine alloys, Corrosion 24 (1968) 127-133

[2] J.A. Goebel, F.S. Pettit, G.W. Goward, Mechanisms for hot corrosion of nickel-base alloys, Metall. Trans. 4 (1973) 261-278

[3] J. Stringer, Hot corrosion of high-temperature alloys, Annu. Rev. Mater. Sci. 7 (1977) 477-509

[4] R.A. Rapp, Chemistry and electrochemistry of the hot corrosion of metals, Corrosion 42 (1986) 568-577

[5] G.W. Goward, Low-temperature hot corrosion in gas-turbines - A review of causes and coatings therefor, J. Eng. Gas Turb. Power 2 (1986) 421-425

[6] N. Birks, G.H. Meier, F.S. Pettit, Introduction to the High Temperature Oxidation of Metals, 2nd edition, Cambridge University Press, Cambridge, 2006

[7] F.S. Pettit, Hot corrosion of metals and alloys, Oxid. Met. 76 (2011) 1-21

[8] K.L. Luthra, D.A. Shores, Mechanism of $\mathrm{Na}_{2} \mathrm{SO}_{4}$ induced corrosion at $600^{\circ}-900^{\circ} \mathrm{C}, \mathrm{J}$. Electrochem. Soc. 127 (1980) 2202-2210

[9] J.A. Goebel, F.S. Pettit, $\mathrm{Na}_{2} \mathrm{SO}_{4}$-induced accelerated oxidation (hot corrosion) of nickel, Metall. Trans. 1 (1970) 1943-1954

[10] I. Barin, Thermochemical Data of Pure Substances, 2nd ed., Weinheim: VCH, 1993

[11] P. Waldner and A.D. Pelton, Thermodynamic modeling of the Ni-S system, Z. Metallkd. 95 (2004) 672-681

[12] B.J. Shaiu, P.C.S. Wu, P. Chiotti, Thermodynamic properties of double oxides of $\mathrm{NaO}$ with oxides of $\mathrm{Cr}$, Ni and Fe, J. Nucl. Mater. 67 (1977) 13-23

[13] D.K. Gupta, R.A. Rapp, The solubilities of $\mathrm{NiO}, \mathrm{Co}_{3} \mathrm{O}_{4}$, and ternary oxides in fused $\mathrm{Na}_{2} \mathrm{SO}_{4}$ at $1200^{\circ} \mathrm{K}$, J. Electrochem. Soc. 127 (1980) 2194-2202

[14] L.C. Li, F. Gesmundo, F. Viani, The construction of isothermal quaternary phasediagrams of the Na-M-O-S type for hot corrosion applications, Oxid. Met. 40 (1993) 395-419 [15] A.K. Misra, D.P. Whittle, W.L. Worrell, Thermodynamics of molten sulfate mixtures, J. Electrochem. Soc. 129 (1982) 1840-1845 
[16] Y.S. Hwang, R.A. Rapp, Synergistic dissolution of oxides in molten sodium sulfate, J. Electrochem. Soc. 137 (1990) 1276-1280

[17] R.A. Rapp, K.S. Goto, "Hot corrosion of metals by molten salts", in J. Braunstein, J.R. Selman, eds, Second International Symposium on Molten Salts, Pennington, NJ: The Electrochemical Society, 1981

[18] K.L. Luthra, Low-temperature hot corrosion of cobalt-base alloys. 1. Morphology of the reaction product, Metall. Trans. A 13 (1982) 1843-1852

[19] K.L. Luthra, Low-temperature hot corrosion of cobalt-base alloys. 2. Reaction mechanism, Metall. Trans. A 13 (1982) 1853-1864

[20] K.P. Lillerud, P. Kofstad, Sulfate-induced hot corrosion of nickel, Oxid. Met. 21 (1984) 233-270

[21] F. Gesmundo, D.J. Young, S.K. Roy, The high temperature corrosion of metals in sulfidizing-oxidizing environments: a critical review, High temperature materials and processes 8 (1989) 149-190

[22] T. Gheno, B. Gleeson, On the hot corrosion of nickel at $700{ }^{\circ} \mathrm{C}$, Oxid. Met. 2015, in press

[23] P. Lortrakul, R.W. Trice, K.P. Trumble, M.A. Dayananda, Investigations of the mechanisms of Type-II hot corrosion of superalloy CMSX-4, Corros. Sci. 80 (2014) 408-415

[24] J. Sumner, A. Encinas-Oropesa, N.J. Simms, J.R. Nicholls, Type II hot corrosion: kinetics studies of CMSX-4, Oxid. Met. 80 (2013) 553-563

[25] J. Sumner, A. Encinas-Oropesa, N.J. Simms, J.R. Nicholls, Type II hot corrosion: Behavior of CMSX-4 and IN738LC as a function of corrosion environment, Mater. Corros. 65 (2014) 188-196

[26] M.N. Task, B. Gleeson, F.S. Pettit, G.H. Meier, Compositional factors affecting protective alumina formation under type II hot corrosion conditions, Oxid. Met. 80 (2013) 541-552

[27] Materials Preparation Center, Ames Laboratory USDOE, Ames IA, USA

[28] P.W.S.K. Bandaranayake, B.-E. Mellander, Phase transitions and ionic conductivity of the $\mathrm{Na}_{2} \mathrm{SO}_{4}-\mathrm{MgSO}_{4}$ system, Solid State Ionics 40 (1990) 31-33

[29] V.K. Tolpygo, D.R. Clarke, Microstructural study of the $\theta-\alpha$ transformation in alumina scales formed on nickel aluminides, Mater. High. Temp. 17 (2000) 59-70

[30] N. Dupin, I. Ansara, B. Sundman, Thermodynamic re-assessment of the ternary system Al-Cr-Ni, Calphad 25 (2001) 279-298

[31] Z. Zhang, L. Li, J. Yang, $\gamma-\mathrm{Al}_{2} \mathrm{O}_{3}$ thin film formation via oxidation of $\beta-\mathrm{NiAl}(110)$, Acta Mat. 59 (2011) 5905-5916

[32] E.M. Levin, H.F. McMurdie, Phase diagrams for ceramists 1975 supplement, Westerville, OH: Am Ceram Soc, 1975

[33] M.W. Brumm, H.J. Grabke, B. Wagemann, The oxidation of NiAl. 3. Internal and intergranular oxidation, Corros. Sci. 36 (1994) 37-53

[34] B. Schramm, W. Auer, Sulfidation behaviour of nickel aluminides, Mater. Corros. 47 (1996) 678-684

[35] H.J. Grabke, G.H. Meier, Accelerated oxidation, internal oxidation, intergranular oxidation, and pesting of intermetallic compounds, Oxid. Met. 44 (1995) 147-176

[36] J.A. Goebel, F.S. Pettit, Influence of sulfides on oxidation behavior of nickel-base alloys, Metall. Trans. 1 (1970) 3421-3429

[37] J. Smialek, Non-protective alumina growth in sulfur-doped NiAl(Zr), Mater. High. Temp. 17 (2000) 71-77 
[38] M.G. Lawson, F.S. Pettit, J.R. Blachere, Hot corrosion of alumina, J. Mater. Res. 8 (1993) 1964-1971

[39] P.D. Jose, D.K. Gupta, R.A. Rapp, Solubility of $\alpha-\mathrm{Al}_{2} \mathrm{O}_{3}$ in fused $\mathrm{Na}_{2} \mathrm{SO}_{4}$ at $1200 \mathrm{~K}$, J. Electrochem. Soc. 132 (1985) 735-737

[40] A. Rahmel, M. Schmidt, M. Schorr, The influence of electrode potential on the corrosion of gas-turbine alloys in sulfate melts, Oxid. Met. 18 (1982) 195-223

[41] W.T. Wu, A. Rahmel, Inhibition of hot corrosion by $\mathrm{MgSO}_{4}$ and $\mathrm{BaSO}_{4}$ and its potential dependence, Werkst. Korros. 35 (1984) 139-149

[42] Y.S. Zhang, Solubilities of $\mathrm{Cr}_{2} \mathrm{O}_{3}$ in fused $\mathrm{Na}_{2} \mathrm{SO}_{4}$ at $1200 \mathrm{~K}$, J. Electrochem. Soc. 133 (1986) 655-657

[43] M. Fukumoto, T. Suzuki, M. Sano, M. Hirade, M. Hara, Solubility of metal oxides under control of basicity by electrolysis in fused $\mathrm{Na}_{2} \mathrm{SO}_{4}$, Mater. Trans. 45 (2004) 2994-2998

[44] G.W. Goward, Protective coatings - purpose, role, and design, Mater. Sci. Tech. 2 (1986) 194-200

[45] D.L. Ellis, Hot corrosion of the B2 nickel aluminides, CR191082, NASA, 1993

[46] J.A. Nesbitt, Hot corrosion of single-crystal NiAl-X alloys, TM113128, NASA, 1998

[47] C. Leyens, B.A. Pint, I.G. Wright, Effect of composition on the oxidation and hot corrosion resistance of NiAl doped with precious metals, Surf. Coat. Tech. 133-134 (2000) $15-22$

[48] G.J. Santoro, C.A. Barrett, Hot corrosion resistance of nickel-chromium-aluminum alloys, J. Electrochem. Soc. 125 (1978) 271-278

[49] K.L. Luthra, Kinetics of the low-temperature hot corrosion of Co-Cr-Al alloys, J. Electrochem. Soc. 132 (1985) 1293-1298

[50] W.T. Wu, A. Rahmel, M. Schorr, Acidic and basic fluxing of Ni-base superalloys in a $90 \mathrm{Na}_{2} \mathrm{SO}_{4}-10 \mathrm{~K}_{2} \mathrm{SO}_{4}$ melt at $1173 \mathrm{~K}$, Oxid. Met. 19 (1983) 201-229

[51] P. Kofstad, High Temperature Corrosion, London: Elsevier, 1988, p. 489

\section{Figure Captions}

Figure 1: Stability diagrams of the (a) Na-Al-O-S, (b) Na-Ni-O-S, and (c) Na-Cr-O-S systems at $700{ }^{\circ} \mathrm{C}$, constructed from thermodynamic data in Refs. [10,11] and making the assumption of unit activity for all compounds. Standard states for all gases and condensed phases are states of the pure phases at $10^{5} \mathrm{~Pa}$. Phase boundaries in the Na-O-S system are superimposed. The metastable $\gamma-\mathrm{Al}_{2} \mathrm{O}_{3}$ was identified experimentally in the present work, and was therefore chosen in (a) instead of the stable polymorph $\alpha$. In (b), the mixed compounds $\mathrm{Na}_{2} \mathrm{NiO}_{2}$ and $\mathrm{NaNiO}_{2}$ are missing, because of a lack of data (emf results by Shaiu et al [12], although used by several authors [13,14], were deemed unreliable by Shaiu et al. themselves). The vertical dotted line in (b) represents the equilibrium between $\mathrm{NiO}$ (s), $\mathrm{Na}_{2} \mathrm{SO}_{4}-\mathrm{NiSO}_{4}$ (s) and $\mathrm{Na}_{2} \mathrm{SO}_{4}-\mathrm{NiSO}_{4}$ (l) according to Misra et al. [15] (see text). The cross represents the equilibrium composition of an $\mathrm{O}_{2}-0.1 \% \mathrm{SO}_{2}$ gas mixture.

Figure 2: XRD patterns of the NiAl and NiAlCr alloys, in as-received condition (BraggBrentano $\theta-\theta$ configuration) and after $20 \mathrm{~h}$ oxidation in air at $700{ }^{\circ} \mathrm{C}$ (grazing angle, $\Omega=$ $\left.0.5^{\circ}\right)$. 
Figure 3: SEM image of bulk NiAl alloy showing the fine $\mathrm{Ni}_{5} \mathrm{Al}_{3}-\gamma^{\prime}-\beta$ microstructure obtained after $20 \mathrm{~h}$ oxidation in air at $700^{\circ} \mathrm{C}$ (cross-section).

Figure 4: TEM analysis of corrosion products formed on $\mathrm{NiAl}$ exposed $2 \mathrm{~h}$ to $\mathrm{Na}_{2} \mathrm{SO}_{4}$ in $\mathrm{O}_{2}$ $0.1 \mathrm{SO}_{2}$ at $700{ }^{\circ} \mathrm{C}$. (a) STEM image showing thin $\mathrm{Al}_{2} \mathrm{O}_{3}$ scale and thicker intrusion; (b) bright field image of an intrusion; (c) SAD pattern from the intrusion (location of SAD aperture shown in (b)) and superimposed $\gamma-\mathrm{Al}_{2} \mathrm{O}_{3}$ ring pattern; (d) X-ray maps of an intrusion.

Figure 5: SEM image of nodule grown on NiAl alloy after $20 \mathrm{~h}$ exposure to $\mathrm{Na}_{2} \mathrm{SO}_{4}$ in $\mathrm{O}_{2}$ $0.1 \mathrm{SO}_{2}$ at $700{ }^{\circ} \mathrm{C}$. The insert shows a region of intact $\mathrm{Al}_{2} \mathrm{O}_{3}$ scale and an early-stage disruption of the scale, on the same sample.

Figure 6: NiAlCr alloy after $2 \mathrm{~h}$ exposure to $\mathrm{Na}_{2} \mathrm{SO}_{4}$ in $\mathrm{O}_{2}-0.1 \mathrm{SO}_{2}$ at $700{ }^{\circ} \mathrm{C}$. (a) SEM image; (b) TEM image and X-ray maps of oxide scale and subscale region.

Figure 7: SEM images of NiAlCr after (a) $6.5 \mathrm{~h}$ and $(\mathrm{b}, \mathrm{c}) 20 \mathrm{~h}$ exposure to $\mathrm{Na}_{2} \mathrm{SO}_{4}$ in $\mathrm{O}_{2}$ $0.1 \mathrm{SO}_{2}$ at $700{ }^{\circ} \mathrm{C}$. Image (c) shows a region where the sulfate deposit has almost entirely been consumed by reaction with the alloy.

Figure 8: SEM images of $\mathrm{NiAl}$ after $20 \mathrm{~h}$ reaction with (a) $\mathrm{Na}_{2} \mathrm{SO}_{4}$ and (b) $\mathrm{Na}_{2} \mathrm{SO}_{4}-\mathrm{MgSO}_{4}$ in air at $700{ }^{\circ} \mathrm{C}$.

Figure 9: SEM images of (a) $\mathrm{NiAl}$ and (b) NiAlCr after $20 \mathrm{~h}$ reaction with $\mathrm{Na}_{2} \mathrm{SO}_{4}-\mathrm{MgSO}_{4}$ in $\mathrm{O}_{2}-0.1 \mathrm{SO}_{2}$ at $700{ }^{\circ} \mathrm{C}$.

Figure 10: Optical micrographs of $\mathrm{NiAl}$ surface after $20 \mathrm{~h}$ exposure to $\mathrm{Na}_{2} \mathrm{SO}_{4}$ in $\mathrm{O}_{2}-0.1 \mathrm{SO}_{2}$ at $700^{\circ} \mathrm{C}$, and additional $20 \mathrm{~h}$ heat treatments in air with no deposit.

Figure 11: SEM image of NiAl after $20 \mathrm{~h}$ exposure to $\mathrm{Na}_{2} \mathrm{SO}_{4}-\mathrm{Cr}_{2} \mathrm{O}_{3}$ mixed deposits in $\mathrm{O}_{2}$ $0.1 \mathrm{SO}_{2}$ at $700{ }^{\circ} \mathrm{C}$, with (a) $5 \times 10^{-3} \mathrm{~mol} \%$; (b) $0.5 \mathrm{~mol} \% \mathrm{Cr}_{2} \mathrm{O}_{3}$.

Figure A1: Equilibrium $\mathrm{Na}_{2} \mathrm{AO}_{2}$ and $\mathrm{SO}_{3}$ activities resulting from $\mathrm{AO}$ dissolution in $\mathrm{Na}_{2} \mathrm{SO}_{4}$ as a function of initial $p_{\mathrm{SO}_{3}}$ (top panel), plotted for $K=10^{-22.19}$ (obtained for $T=700{ }^{\circ} \mathrm{C}$ from Ref. [10]) and an arbitrary $K_{A}=10^{5}$. Standard states for all gases and condensed phases are states of pure phases at $10^{5} \mathrm{~Pa}$. The symbols $\mathrm{Ri}(i=1-3)$ denote the regimes identified in the text. In the intermediate regime (R2), the equilibrium $a_{\mathrm{Na}_{2} \mathrm{AO}_{2}}$ and $p_{\mathrm{SO}_{3}}$ are independent of the initial $p_{\mathrm{SO}_{3}}$ : the $\mathrm{AO} / \mathrm{Na}_{2} \mathrm{AO}_{2}$ couple acts as a buffer. In the acidic regime (R1), the solubility of $\mathrm{AO}$ is very low, little $\mathrm{Na}_{2} \mathrm{AO}_{2}$ is produced, and the ambient $p_{\mathrm{SO}_{3}}$ is not affected. In the bottom panel, the equilibrium $a_{\mathrm{Na}_{2} \mathrm{AO}_{2}}$ is plotted as a function of the equilibrium $p_{\mathrm{SO}_{3}}$ : this is equivalent to a solubility curve. The dashed lines denote four initial $p_{\mathrm{SO}_{3}}$ values shown as examples: two in the buffered regime (R2) which result in the same equilibrium composition, and two in the acidic regime (R1) which are not affected by the limited AO dissolution. 
Figure A2: Equilibrium $\mathrm{BSO}_{4}$ and $\mathrm{SO}_{3}$ activities resulting from $\mathrm{BO}$ dissolution in $\mathrm{Na}_{2} \mathrm{SO}_{4}$ as a function of initial $p_{\mathrm{SO}_{3}}$ (top panel), plotted for $K=10^{-22.19}$ (obtained for $T=700{ }^{\circ} \mathrm{C}$ from Ref. [10]) and an arbitrary $K_{B}=10^{4}$. Standard states for all gases and condensed phases are states of pure phases at $10^{5} \mathrm{~Pa}$. In the intermediate regime (R2), the equilibrium $a_{\mathrm{BSO}_{4}}$ and $p_{\mathrm{SO}_{3}}$ are independent of the initial $p_{\mathrm{SO}_{3}}$ : the $\mathrm{BO} / \mathrm{BSO}_{4}$ couple acts as a buffer. In the bottom panel, the equilibrium $a_{\mathrm{BSO}_{4}}$ is plotted as a function of the equilibrium $p_{\mathrm{SO}_{3}}$. The dashed lines denote two initial $p_{\mathrm{SO}_{3}}$ values in the buffered regime (R2) which result in the same equilibrium composition.

Figure A3: Equilibrium $\mathrm{Na}_{2} \mathrm{AO}_{2}, \mathrm{BSO}_{4}$ and $\mathrm{SO}_{3}$ activities resulting from simultaneous $\mathrm{AO}$ and BO dissolution in $\mathrm{Na}_{2} \mathrm{SO}_{4}$ as a function of initial $p_{\mathrm{SO}_{3}}$ (top panel), plotted for $K=10^{-22.19}$ (obtained for $T=700{ }^{\circ} \mathrm{C}$ from Ref. [10]) and arbitrary $K_{A}=10^{5}$ and $K_{B}=10^{4}$. Standard states for all gases and condensed phases are states of pure phases at $10^{5} \mathrm{~Pa}$. In the intermediate regime (R2), the equilibrium $a_{\mathrm{Na}_{2} \mathrm{AO}_{2}}, a_{\mathrm{BSO}_{4}}$ and $p_{\mathrm{SO}_{3}}$ are independent of the initial $p_{\mathrm{SO}_{3}}$ : the $\mathrm{AO} / \mathrm{Na}_{2} \mathrm{AO}_{2} / \mathrm{BO} / \mathrm{BSO}_{4}$ quadruplet acts as a buffer. In the bottom panel, the equilibrium $a_{\mathrm{Na}_{2} \mathrm{AO}_{2}}$ and $a_{\mathrm{BSO}_{4}}$ are plotted as a function of the equilibrium $p_{\mathrm{SO}_{3}}$. The dashed lines denote two initial $p_{\mathrm{SO}_{3}}$ values in the buffered regime (R2) which result in the same equilibrium composition.

\section{Tables}

Table 1: Phase constitution of the model alloys before and after $20 \mathrm{~h}$ oxidation in dry air at $700^{\circ} \mathrm{C}$. gb: grain boundaries; $\beta^{\prime}$ : L10 martensite.

\begin{tabular}{|c|c|c|c|c|c|c|c|}
\hline \multirow[b]{3}{*}{ Alloy } & \multicolumn{4}{|c|}{ Experimental (XRD, EPMA) } & \multicolumn{3}{|c|}{ Literature } \\
\hline & \multicolumn{2}{|c|}{ As-received } & \multicolumn{2}{|c|}{ After oxidation } & \multirow{2}{*}{$1150^{\circ} \mathrm{C}$} & \multirow{2}{*}{$700^{\circ} \mathrm{C}$} & \multirow{2}{*}{ Ref } \\
\hline & bulk & $\mathrm{gb}$ & bulk & $\mathrm{gb}$ & & & \\
\hline $\mathrm{NiAl}$ & $\beta^{\prime}+\beta$ & $\gamma^{\prime}$ & $\beta+\mathrm{Ni}_{5} \mathrm{Al}_{3}+\gamma^{\prime}$ & $\gamma^{\prime}$ & $\beta$ & $\beta+\gamma^{\prime}$ & [30] \\
\hline $\mathrm{NiAlCr}$ & $\beta$ & & $\beta$ & $\gamma^{\prime}$ & $\beta$ & $\beta+\gamma^{\prime}+\alpha$ & [30] \\
\hline
\end{tabular}




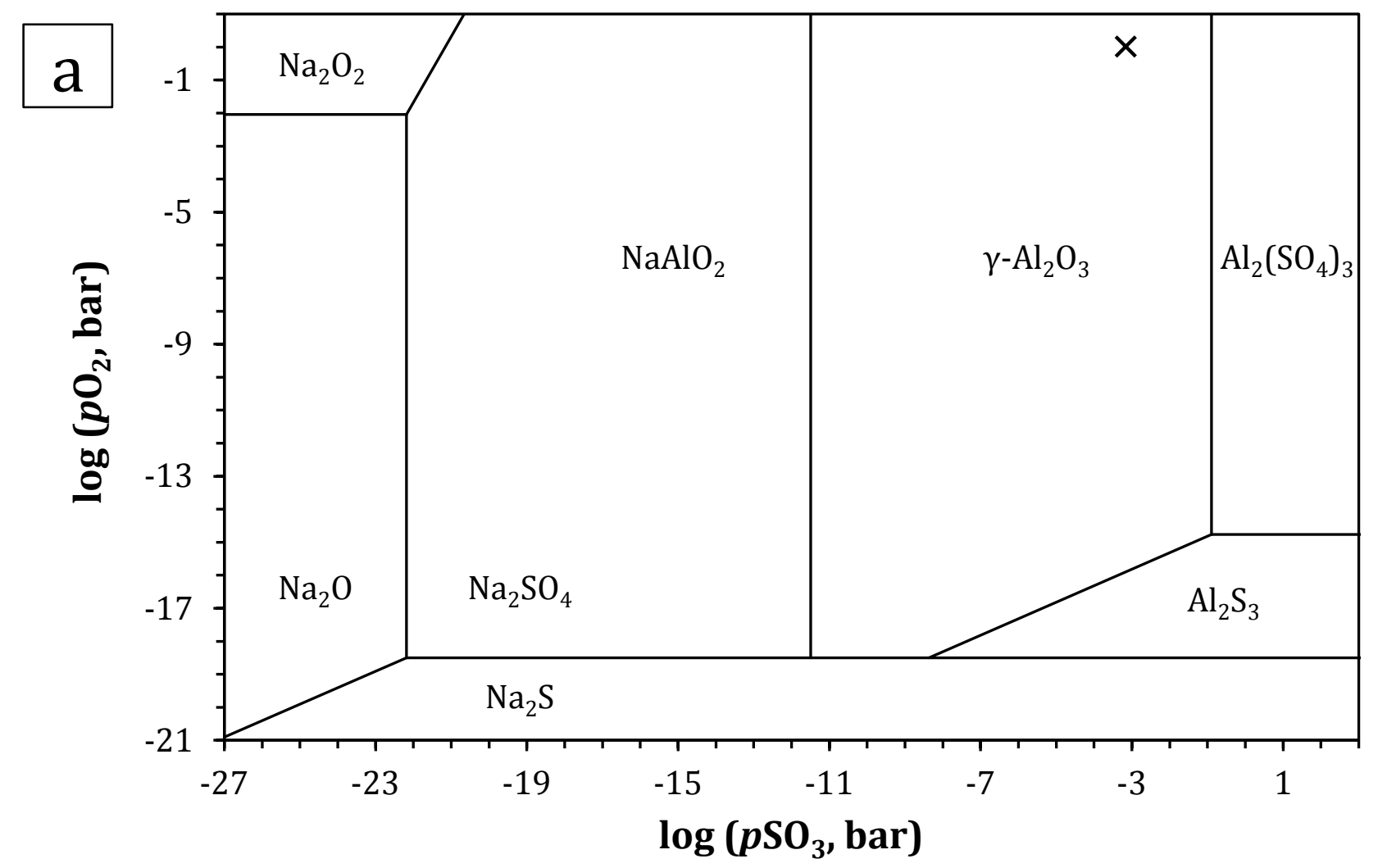




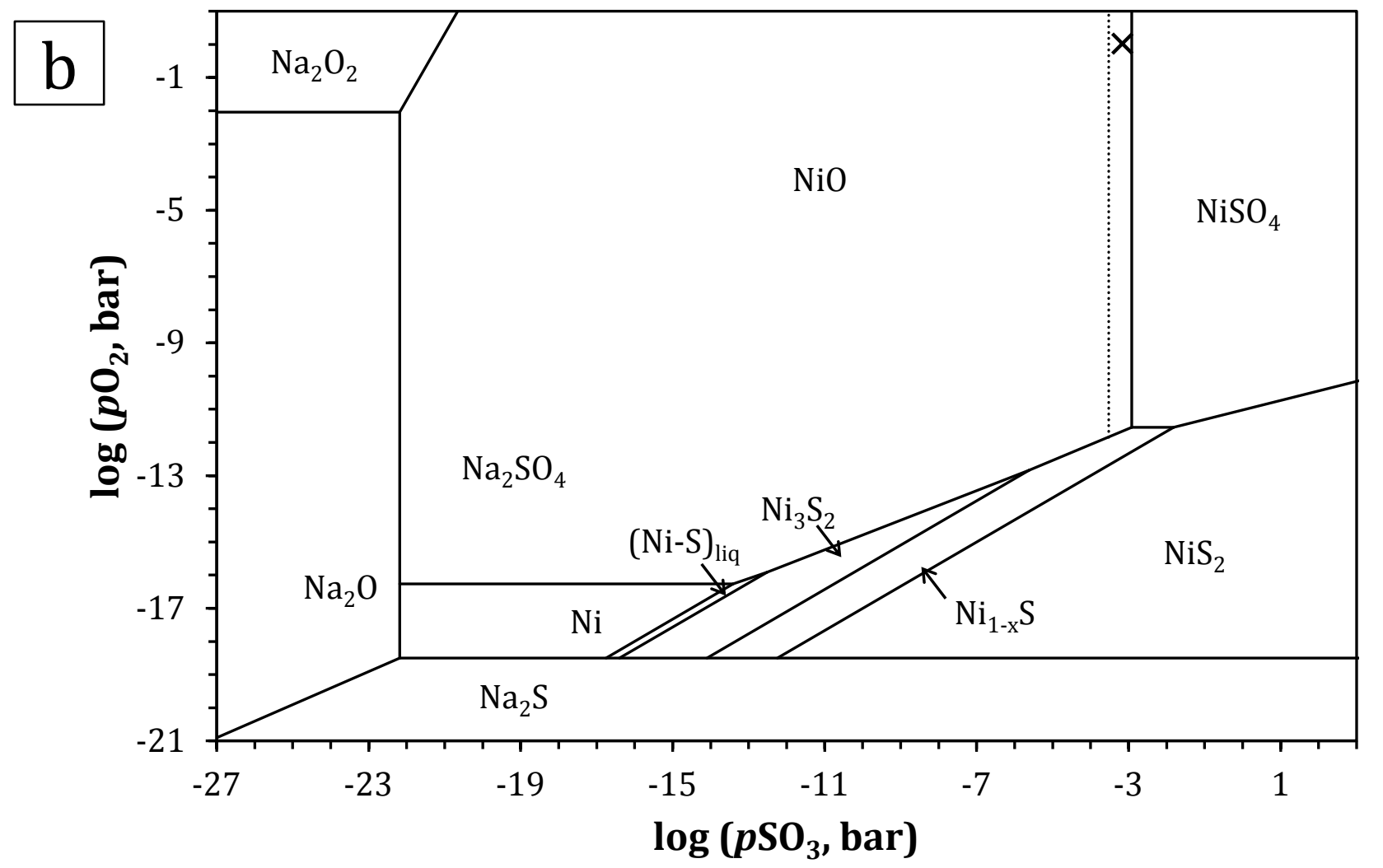




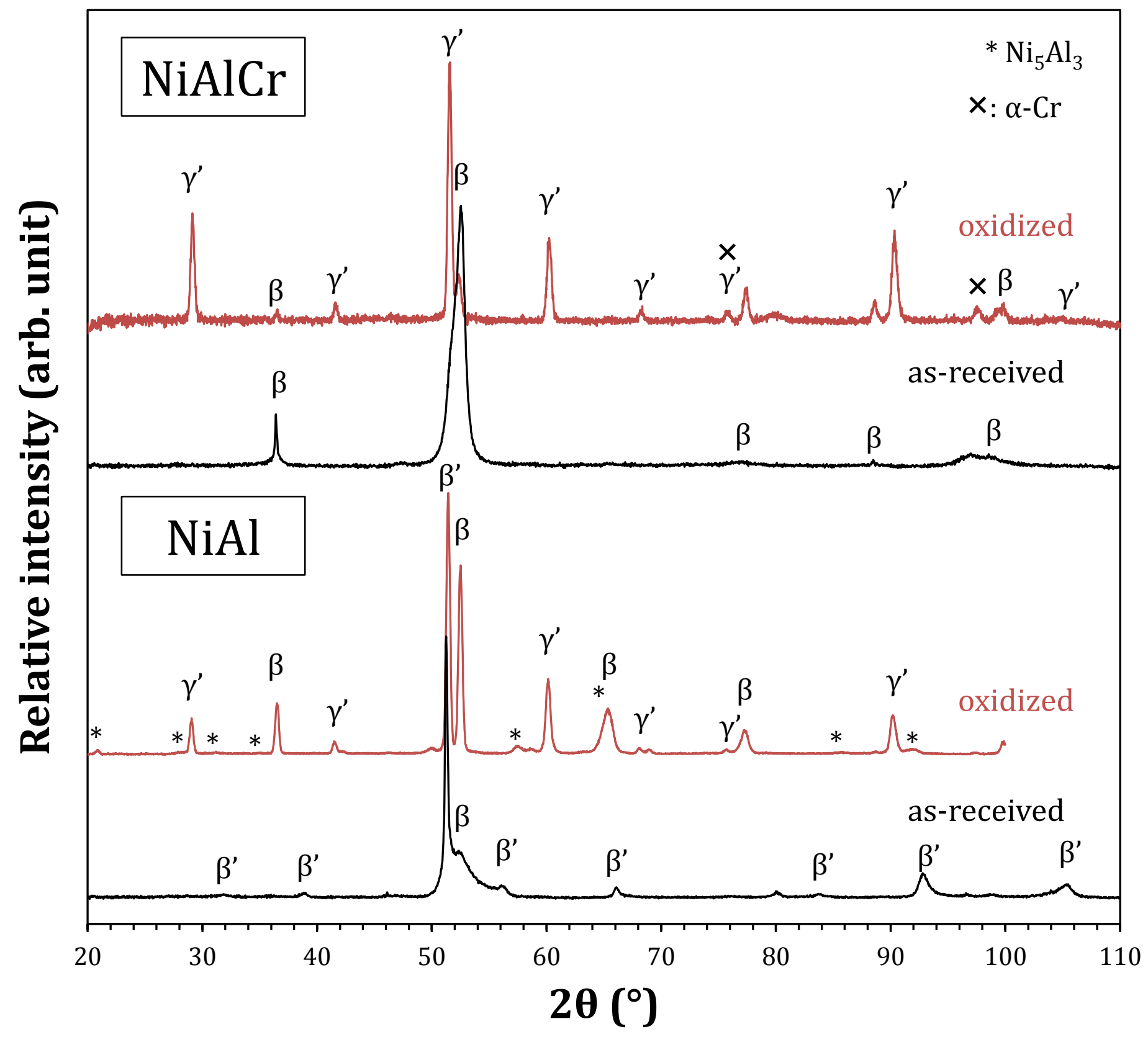


The

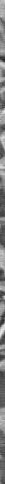




$$
\mathrm{Al}_{2} \mathrm{O}_{3} \text { scale }
$$




\section{b}

$500 \mathrm{~nm}$

$8 \mathrm{~nm}^{-1}$

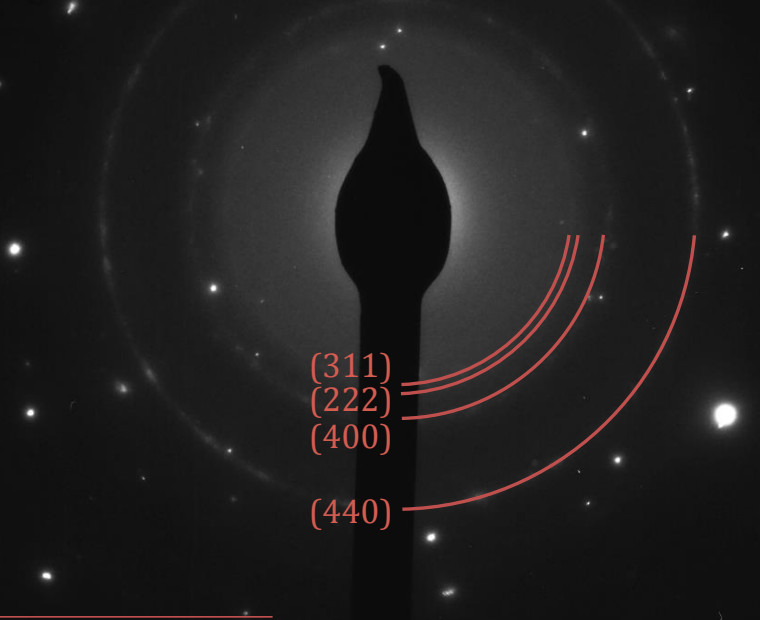




\section{d}

0

$1 \mu \mathrm{m}$

$\mathrm{Al}$

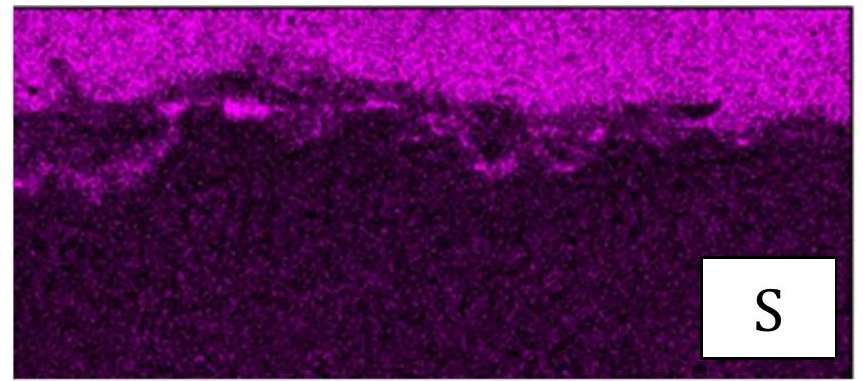




\section{$\mathrm{NiO}+\mathrm{NiAl}_{2} \mathrm{O}_{4}$}

\section{$20 \mu \mathrm{m}$}

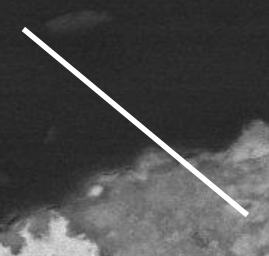

$5+2$
3 - 353

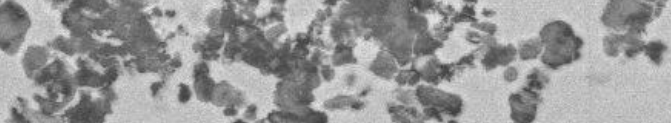
के

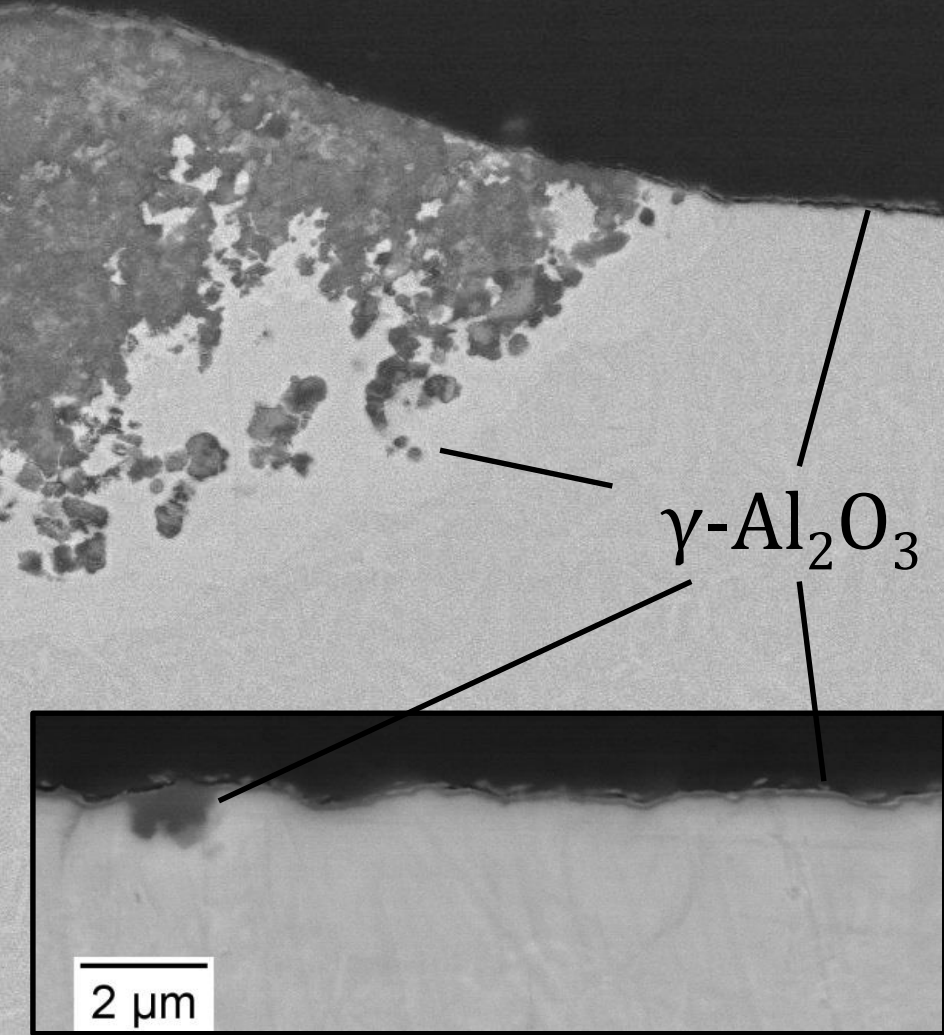


a

\section{mixed sulfate}

\section{$5 \mu \mathrm{m}$}

$\gamma^{\prime}+$ mixed sulfide
Ni-rich sulfide
Al-rich oxide 

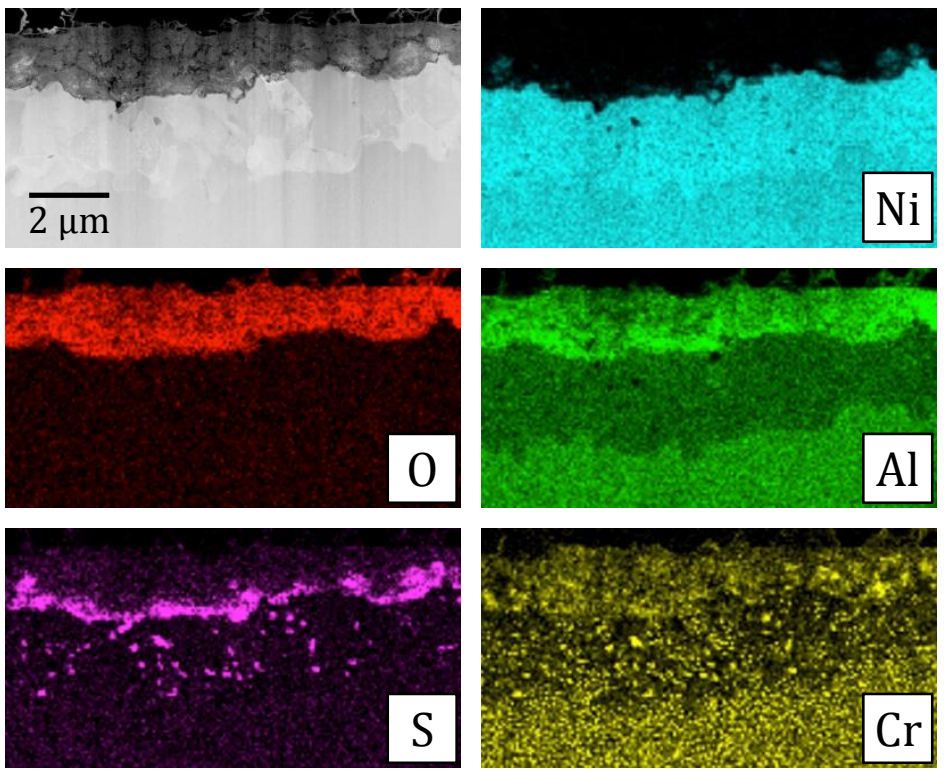
a mixed sulfate $\quad \mathrm{Na}_{2} \mathrm{SO}_{4}$ $(\sim 1 \mathrm{Ni},<1 \mathrm{Al})$
Ni-rich oxide
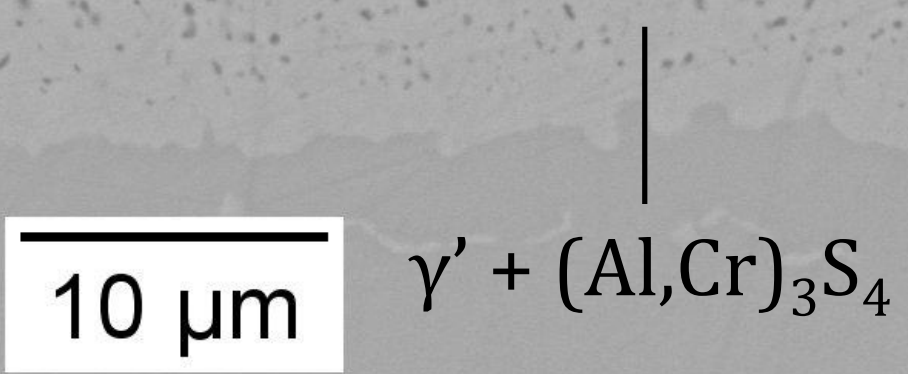

Ni-rich

Al-rich sulfide oxide 


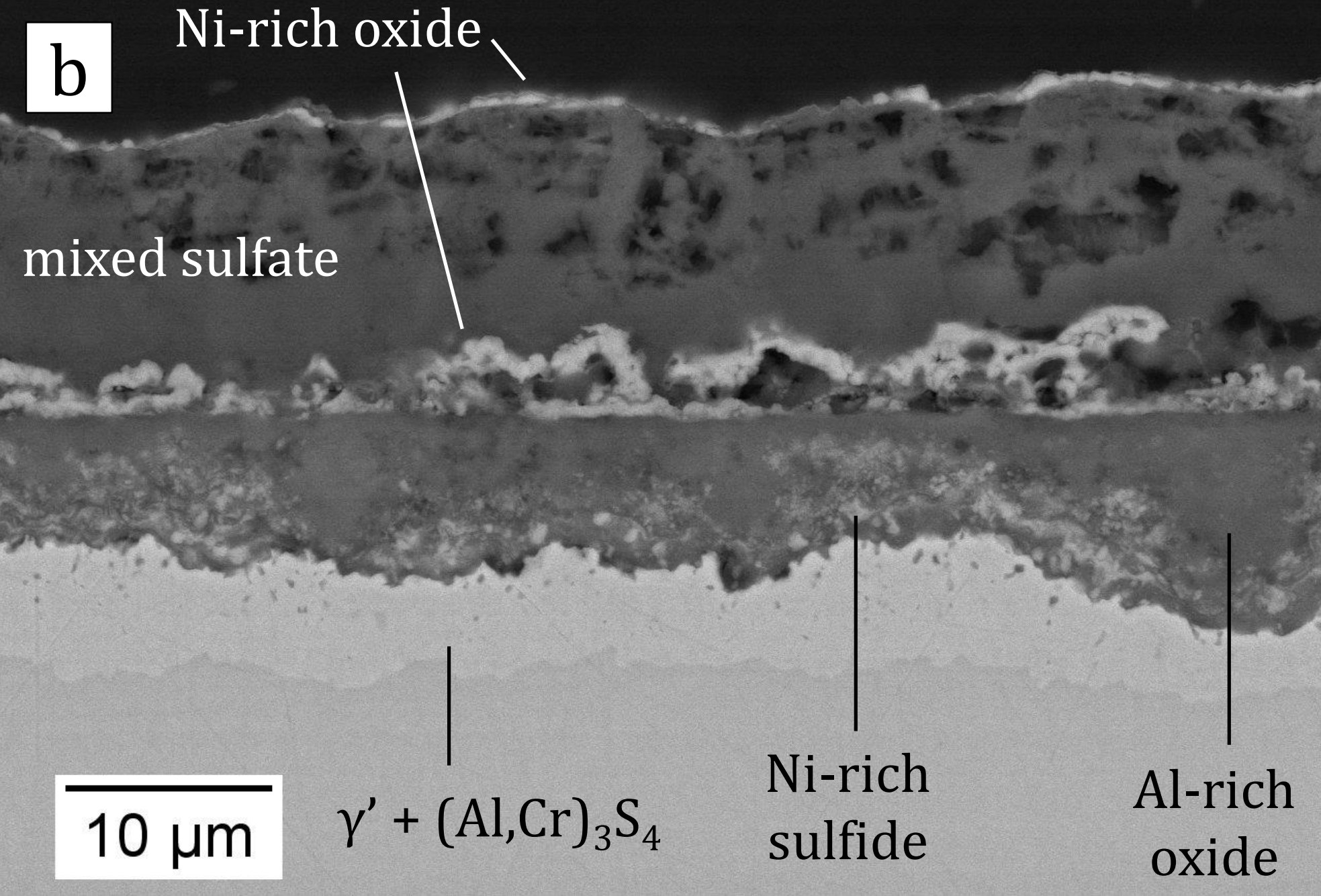




\section{Ni-rich oxide}

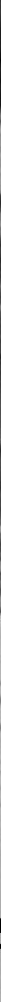


a

$\mathrm{Na}_{2} \mathrm{SO}_{4}$ 1

mixed sulfate

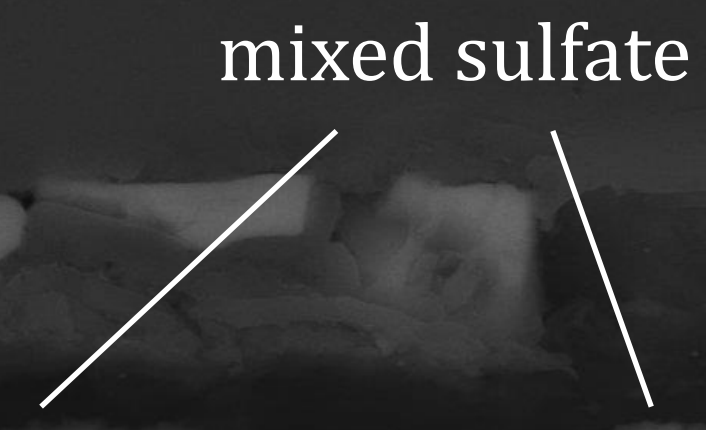

thin $\mathrm{Al}_{2} \mathrm{O}_{3}$

scale
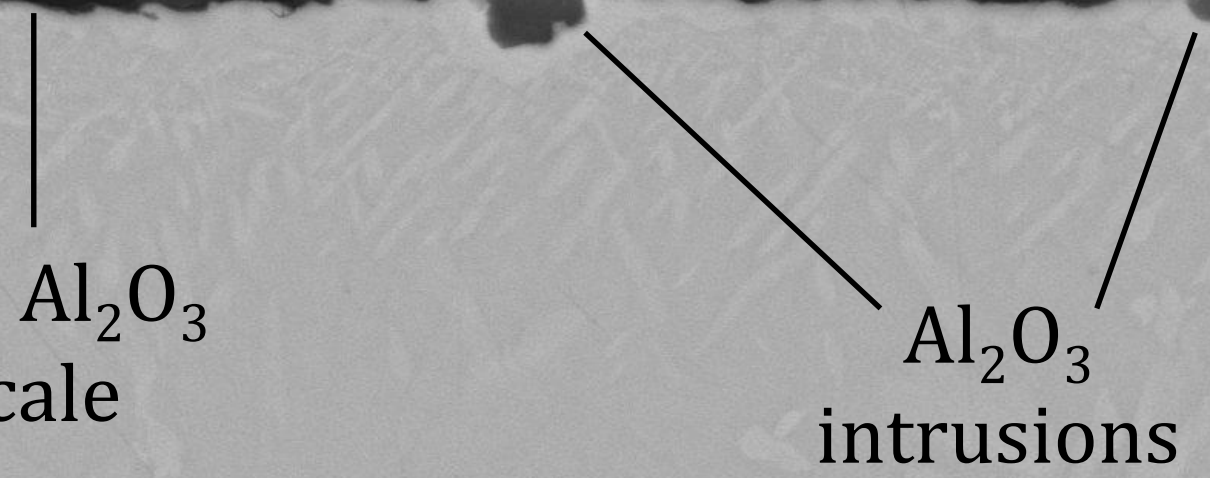

$10 \mu \mathrm{m}$ 
$\mathrm{MgAl}_{2} \mathrm{O}_{4}$

mixed oxidesulfate
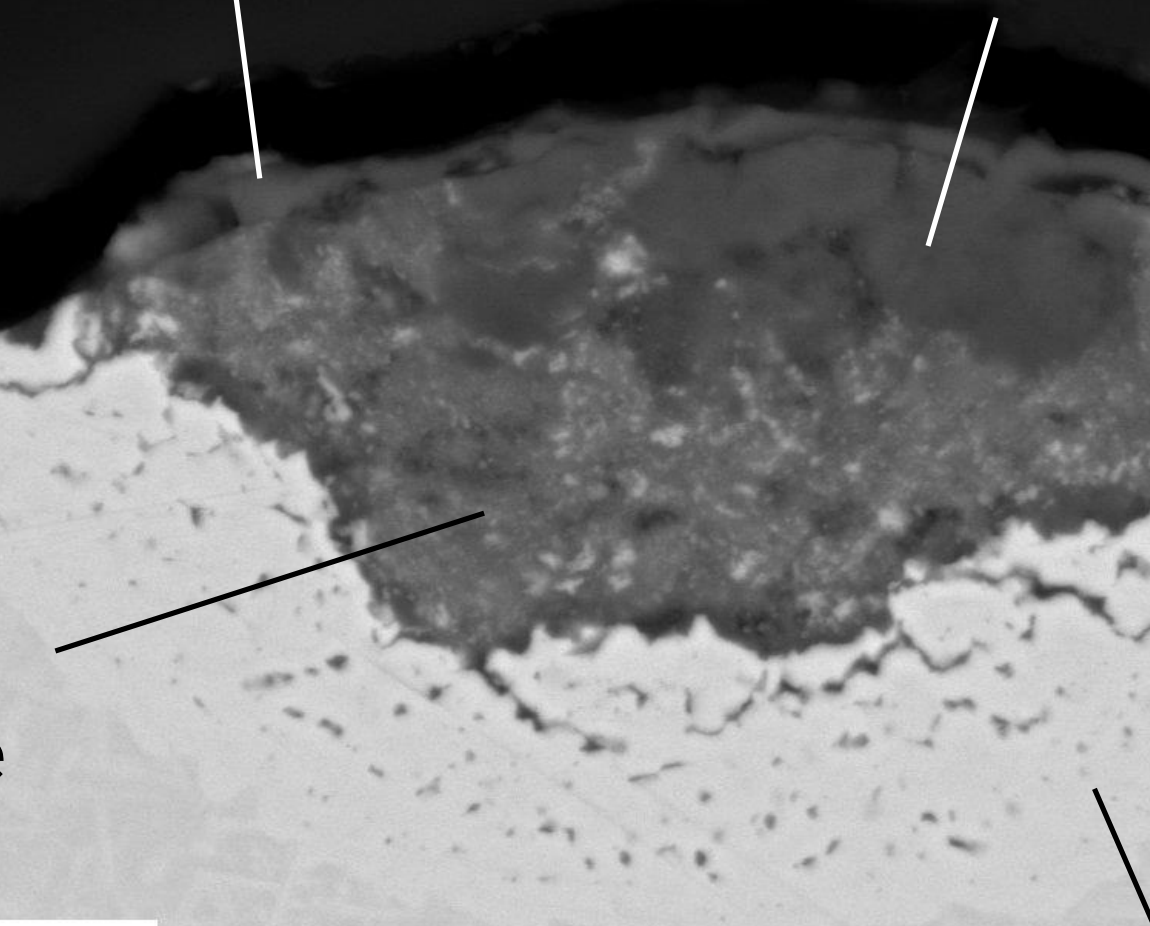
a

\section{mixed oxides-sulfates}

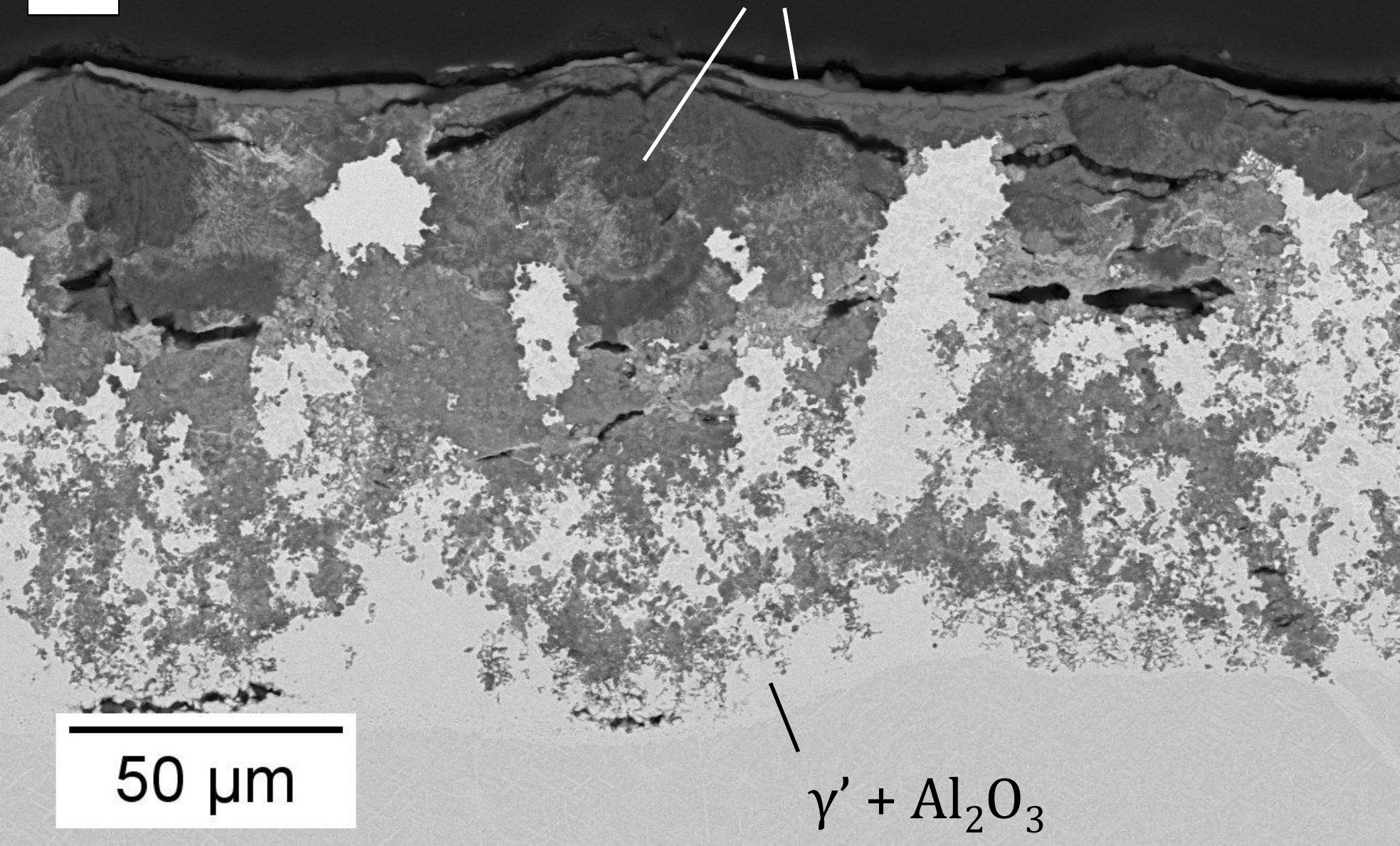




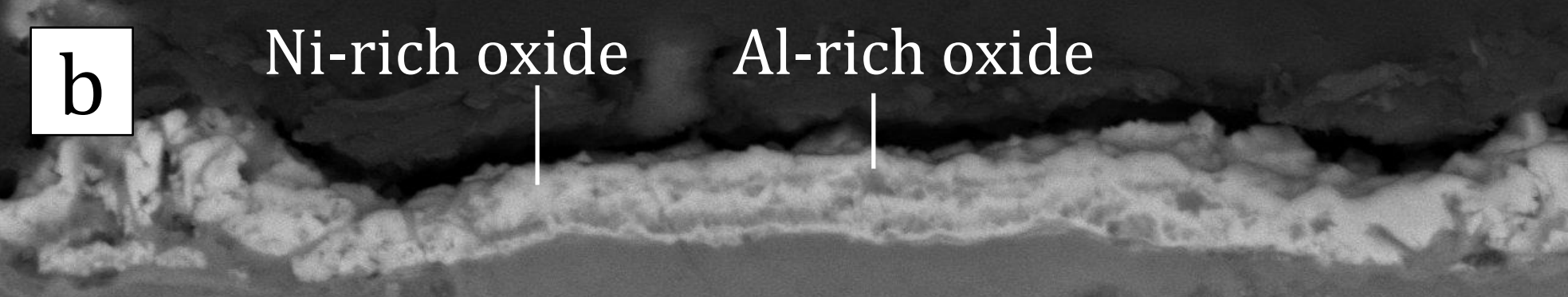

mixed oxide-

sulfate

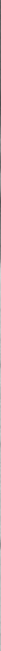

\section{$10 \mu \mathrm{m}$}

$\gamma^{\prime}+$ mixed sulfide 
$20 \mathrm{~h}$ in $\mathrm{O}_{2}-0.1 \mathrm{SO}_{2} \quad$ deposit washed off, with $\mathrm{Na}_{2} \mathrm{SO}_{4}$

$+20 \mathrm{~h}$ in air

$+40 \mathrm{~h}$ in air

$+60 \mathrm{~h}$ in air
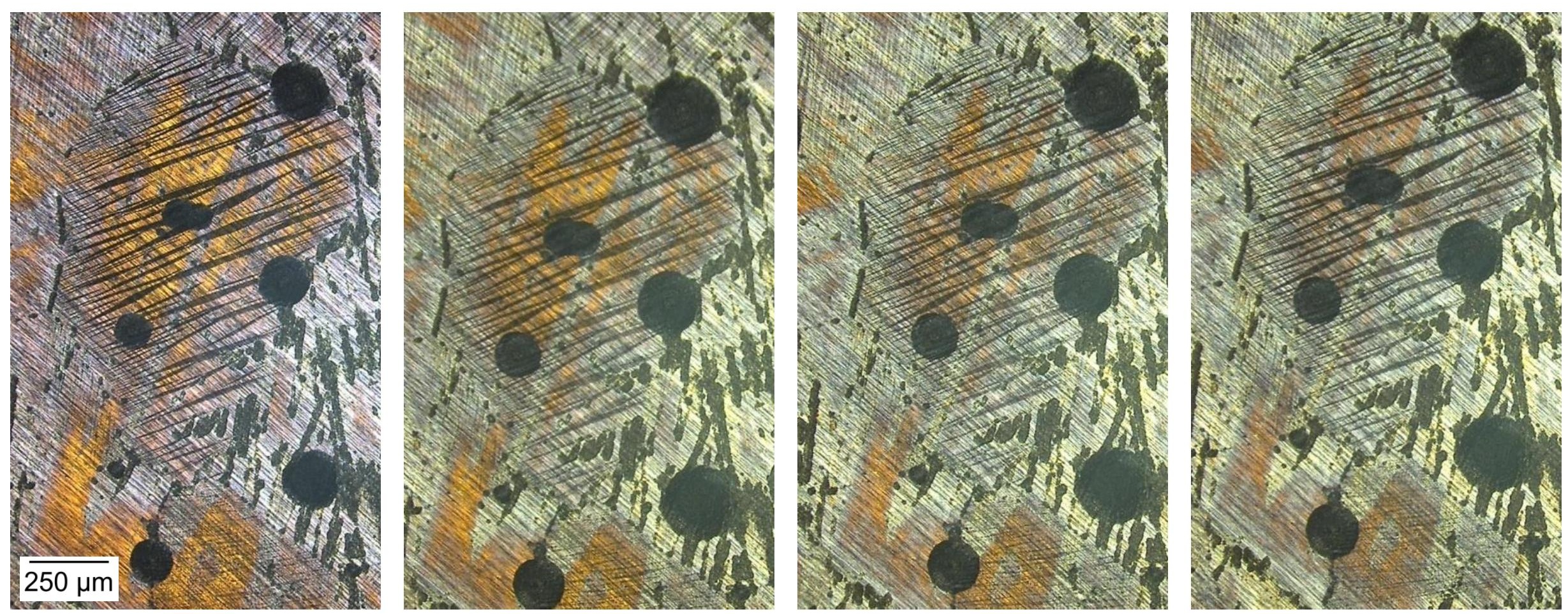
a $\quad \mathrm{NiO}+\mathrm{NiAl}_{2} \mathrm{O}_{4}$

$\mathrm{NiO}$
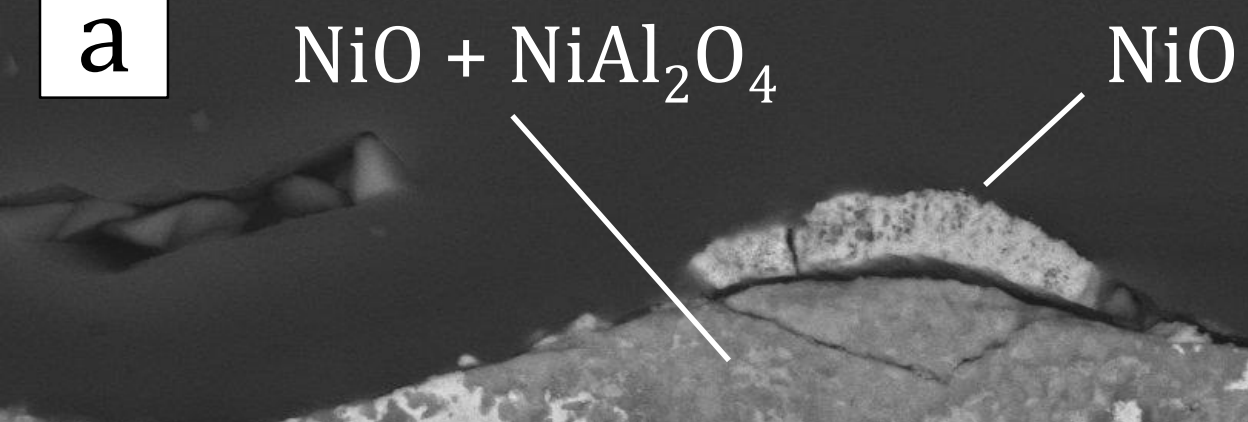

to

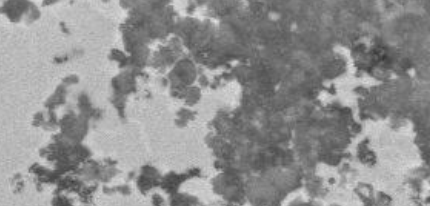

is

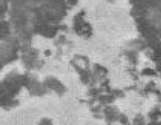

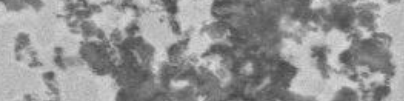
(ब) 10

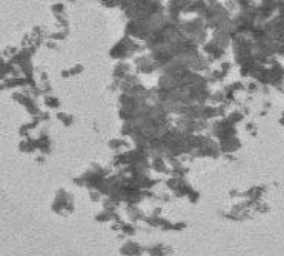

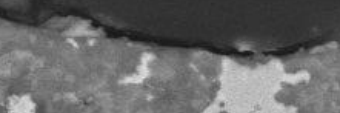

-

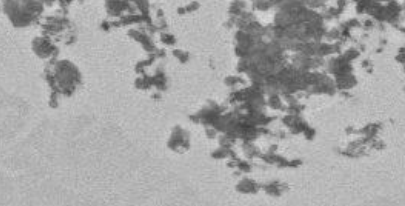

Tit $12 x$

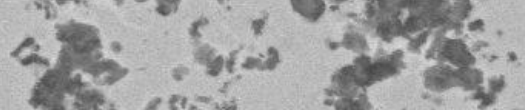

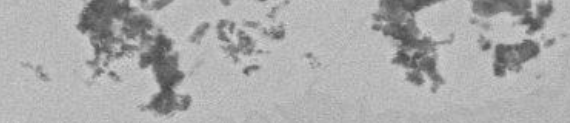

$\mathrm{Al}_{2} \mathrm{O}_{3}$

\section{$20 \mu \mathrm{m}$}




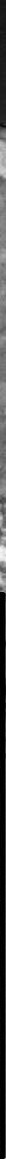




\section{log activity,} equilibrium

$\log a_{\mathrm{Na}_{2} \mathrm{AO}_{2}}$, equilibrium

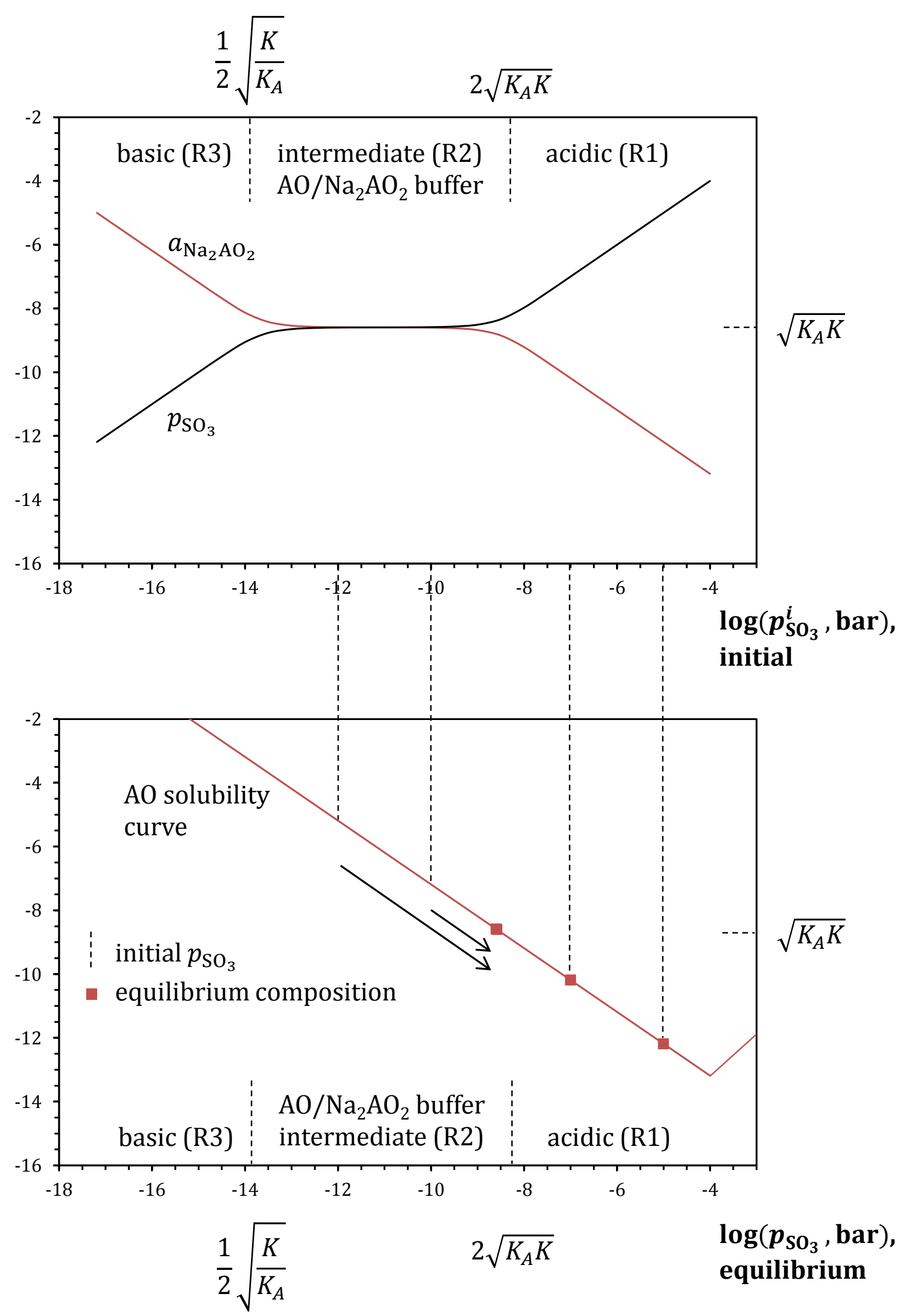




$$
\frac{1}{2} \sqrt{\frac{K}{K_{B}}} \quad 2 \sqrt{K_{B} K}
$$

\section{log activity,} equilibrium

$\log a_{\mathrm{BSO}_{4}}$, equilibrium
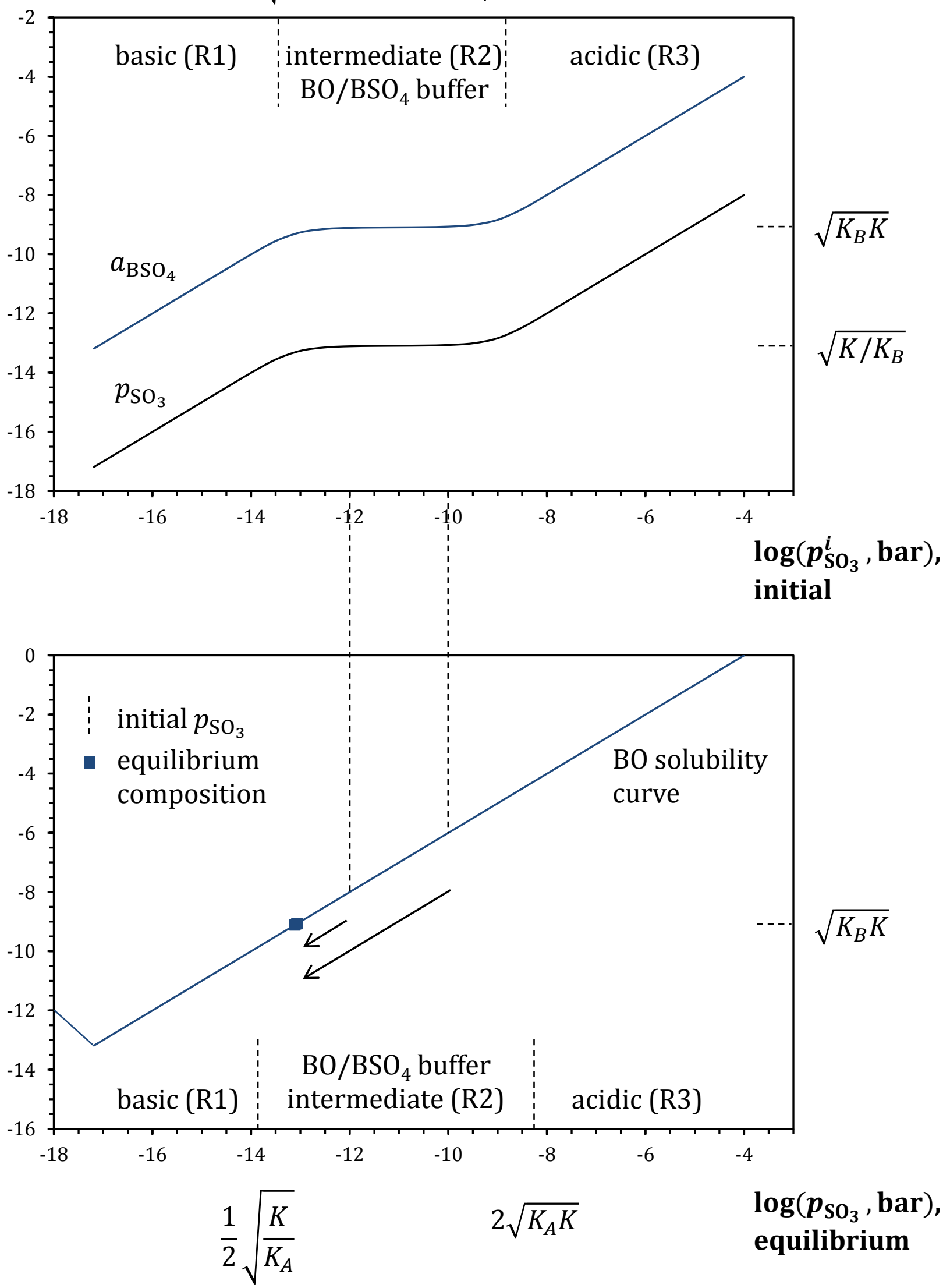


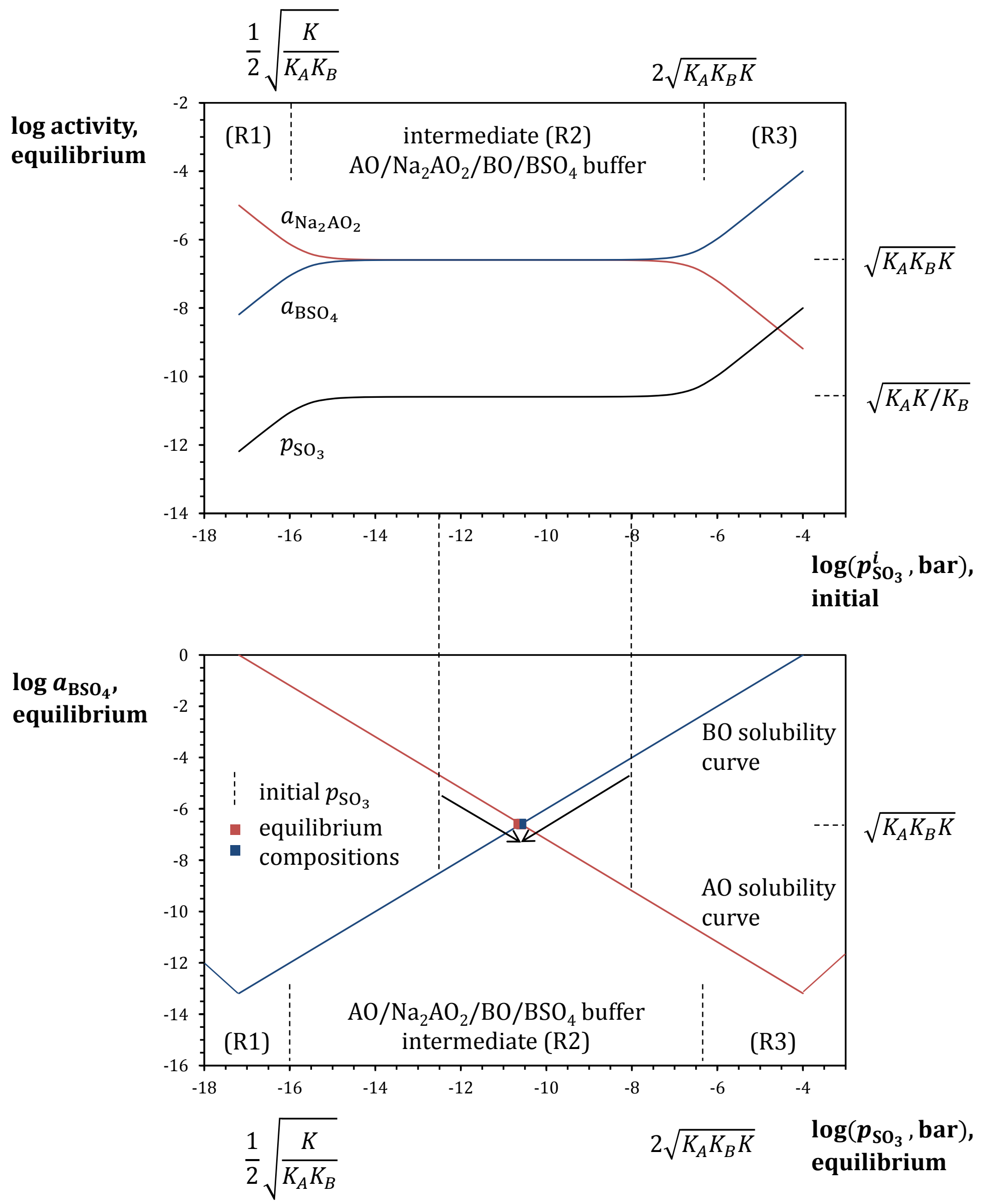

